\title{
Activity of Descending Propriospinal Axons in the Turtle Hindlimb Enlargement during Two Forms of Fictive Scratching: Phase Analyses
}

\author{
Ari Berkowitz and Paul S. G. Stein \\ Department of Biology, Washington University, St. Louis, Missouri 63130
}

In the preceding companion article (Berkowitz and Stein, 1994b), we showed that many descending propriospinal neurons in the turtle were rhythmically activated during two different motor patterns, fictive rostral scratching and fictive pocket scratching. In this article, we present phase analyses of the activity of each such neuron during fictive scratching. Each neuron's activity was concentrated in a particular phase of the ipsilateral hip flexor muscle nerve (VP-HP) activity cycle; each had a distinct "preferred phase." Each neuron's preferred phase during fictive rostral scratching was similar to its preferred phase during fictive pocket scratching. This result is consistent with the idea that some descending propriospinal neurons may contribute to the generation of both rostral scratching and pocket scratching.

Many descending propriospinal neurons were rhythmically activated during fictive scratching evoked on either side of the body. This activity may contribute to production of bilateral hindlimb movements during scratching. It is also possible that synaptic interactions between the two sides of the spinal cord may be important in generating the motor patterns for movement of a single hindlimb.

In addition, we present a model which illustrates that a population of propriospinal neurons, each of which is broadly tuned to a region of the body surface and is rhythmically activated in a constant phase of the hip control cycle, could mediate the selection and generation of rostral scratching and pocket scratching. Thus, the selection of an appropriate motor pattern and the production of the required knee-hip synergy may each be distributed over a diverse population of spinal cord neurons. This model requires that each such neuron project to both knee muscle and hip muscle motoneurons. According to this model, the process of selecting a motor pattern would not be completed until knee muscle motoneurons integrate overlapping excitatory and inhibitory inputs.

[Key words: spinal, interneuron, scratching, fictive, turtle, rhythmic, pattern generation, bilateral]

\footnotetext{
Received Oct. 4, 1993; revised Jan. 19, 1994; accepted Mar. 2, 1994.

We thank Dr. Scott Currie for many useful discussions, Dr. Susan Koester and Edelle Field for valuable comments on the manuscript, and John C. Victor for help with figure preparation. This work was supported by NSF Grant BNS-8908144 to P.S.G.S., NIH Grant NS30786 to P.S.G.S., and an NSF predoctoral fellowship to A.B.

Correspondence should be addressed to Ari Berkowitz, Division of Biology, California Institute of Technology, Pasadena, CA 91125.

Copyright (C) 1994 Society for Neuroscience 0270-6474/94/145105-15\$05.00/0
}

Sequences of muscle or motoneuron activation underlying many rhythmic behaviors in both invertebrates and vertebrates are produced within the CNS by networks of pattern-generating neurons (for a recent review, see Pearson, 1993). The same muscles and motoneurons are often used for several behaviors; in contrast, the motor patterns are distinct for each behavior. The CNS must generate the appropriate motor patterns. In principle, this could be done by having a separate set of CNS neurons for each behavior required. Alternatively, many CNS neurons could contribute to generation of more than one motor pattern. Strong evidence from several well-studied invertebrate systems has demonstrated that CNS pattern-generating neurons often contribute to the production of more than one behavior in invertebrates (see Getting and Dekin, 1985; Dickinson and Moulins, 1992; Kristan et al., 1992; Marder and Weimann, 1992; Heinzel et al., 1993; Pearson, 1993). In a few invertebrate systems, some CNS pattern-generating neurons have been shown to be active during only one of the rhythmic behaviors involving a particular set of motoneurons (Heitler, 1985; Ramirez and Pearson, 1988; Dicaprio, 1990; Hennig, 1992). In vertebrates, however, it is very difficult to obtain conclusive evidence. Due to the large number of neurons involved in generation of each vertebrate behavior, it is unlikely that stimulation or deletion of any one vertebrate neuron will measurably affect the motor pattern produced. Nonetheless, evidence that a large number of CNS neurons are rhythmically activated during generation of more than one rhythmic motor pattern would strongly suggest that some vertebrate pattern-generating neurons also contribute to multiple behaviors.

The spinal control of scratching in turtles provides a good opportunity to study the possible contributions of CNS neurons to generation of multiple rhythmic hehaviors (see Stein, 1989). The turtle spinal cord alone is capable of generating three different forms of scratching by the hindlimb in response to tactile stimulation in an appropriate region of the body surface (Mortin et al., 1985). A distinct motor pattern underlies each form of scratching (Robertson et al., 1985). A seven-segment region of the spinal cord in an immobilized turtle is capable of producing two of these motor patterns, fictive rostral scratching and fictive pocket scratching, in response to tactile stimulation of the appropriate region (Mortin and Stein, 1989). The seven-segment region of the spinal cord was isolated from other regions of the CNS with two spinal transections, the first just rostral to the third postcervical segment (the dorsal 3 or D3 segment) and the second just caudal to the D9 segment. It is shown in the preceding companion article (Berkowitz and Stcin, 1994b) that most descending propriospinal axons recorded in the hindlimb 
enlargement were excited during both fictive rostral scratching and fictive pocket scratching in such turtles. Many of these neurons were rhythmically activated during both forms of fictive scratching. In this article, we present quantitative analyses of the activity of those single neurons that were activated throughout the rostral scratch and pocket scratch receptive fields on at least one side of the body; we analyze their activity with respect to the concurrent scratch motor patterns.

Hip control is a key element in many rhythmic limb behaviors (see Grillner, 1981), including rostral scratching and pocket scratching (see Robertson et al., 1985). Hip protraction (flexion) and hip retraction (extension) alternate in each form of turtle scratching. The relative timing of knee extension within the hip movement cycle distinguishes each form of scratching.(Mortin et al., 1985). For each scratch form, the hindlimb rubs against the stimulated site during knee extension. Knee extension occurs during hip flexion in rostral scratching but during hip extension in pocket scratching. In immobilized turtles (Robertson et al., 1985), knee extensor (FT-KE) motoneurons are active during the burst of hip flexor (VP-HP) motoneuron activity in fictive rostral scratching; FT-KE motoneurons are active during the hurst of hip extensor (HR-KF) activity in fictive pocket scratching. Here, we examine the possibility that the timing of activity in single descending propriospinal neurons was related to the cycle of activity in VP-HP motoneurons during one or both of these forms of scratching. To do so, we developed a "dualreferent" method for phase analysis of single-neuron activity with respect to both the onset and the offset of activity in a muscle nerve. This method was then used to describe the rhythmicity of descending propriospinal neurons with respect to the VP-HP nerve activity cycle during fictive rostral scratching and fictive pocket scratching. The single-unit and motornerve recordings to which this method was applied are described in the preceding companion article (Berkowitz and Stein, 1994b).

The present results have previously been published in abstract form (Berkowitz and Stcin, 1990, 1991, 1992) and in a doctoral thesis (Berkowitz, 1993).

\section{Materials and Methods}

Dual-referent phase histograms. Descending propriospinal axons were recorded in the turtle hindlimb enlargement during tactile elicitation of fictive rostral scratching or fictive pocket scratching. Concurrent recordings were made from the hip protractor (flexor) muscle nerve, VP$\mathrm{HP}$, on both the right and the left sides, while recording from descending propriospinal axons on the right side, in turtles with the D3-D9 spinal cord intact. Several other nerves were also recorded on the right side, including the monoarticular knee extensor muscle nerve, FT-KE. The methods used for recording and stimulation are detailed in the preceding companion article (Berkowite and Stein, 1994b), where we focused on the sensory-related responses of the 104 descending propriospinal neurons recorded. In this article, we use a subset (the 58 motor receptive field units) of this data set to analyze the phase relationships between propriospinal neuron activity and scratch motor patterns. We developed a method to calculate the mean rate of action potential (spike) generation in single neurons in each phase of the activity cycle of a motor nerve (Fig. 1). The VP-HP nerve on the same side as the tactile stimulation generated strong and reliable bursts during fictive rostral scratching and fictive pocket scratching. Thus, this nerve provided a sound basis for single-unit phase analyses. Single-unit phase analyses were performed with respect to the right (ipsilateral) VP-HP nerve for right side stimulations and with respect to the left (contralateral) VP-HP nerve for left side stimulations (see Figs. 7,8). The VP-HP nerve contralateral to the stimulation generated very weak bursts (see Fig. 6; see also Currie and Stein, 1989, their Fig. 5C,D; Berkowitz and Stein, 1994b). Occasionally, it was possible to use the right VP-HP as the basis for single-unit phase analyses during stimulation of either side of the body (see rig. 6).
Each VP-HP nerve activity cycle was defined to begin at the onset of a burst of nerve activity and to end at the onset of the next burst of nerve activity. Each nerve burst (or nerve-active period) was divided into five equal time bins; each nerve-inactive period was also divided into five equal time bins. The single-unit mean firing rate was calculated for each of the 10 bins of each nerve activity cycle, by dividing the number of single-unit spikes in the bin by the bin duration. The singleunit mean firing rates for the first bin of each of several nerve activity cycles were themselves averaged, to obtain a mean value of the mean firing rate for the first bin. The same calculation was performed for each of the other nine bins, yielding the single-unit mean firing rates during 10 phases of the VP-HP activity cycle. Each such calculation was performed on all fictive scratch nerve activity cycles in a data sct obtaincd by mechanical stimulation of a single site on the body surface (on one or more occasion). The values of single-unit mean firing rate in all 10 phases of the nerve activity cycle can be presented graphically, as a "dual-referent phase histogram." Figure 1 illustrates this process for two single descending propriospinal neurons, one strongly rhythmically modulated $(A)$ and the other only very weakly rhythmically modulated $(B)$. Dual-referent phase histograms have been used previously to analyze single-unit activity during rhythmic motor patterns (Orlovsky, 1972; Burns and Usherwood, 1979).

Fictive scratch motor patterns recorded differed in duration of the stimulation episode and in frequency of naturally occurring variations such as HR-KF deletions (Robertson and Stein, 1988; previously termed "B phase deletions" by Stein and Grossman, 1980). To provide comparable and standard data sets for comparison of single-unit activity during tactile stimulation of different sites, the following rules were employed: (1) only cycles with a clear nerve burst and a clear nerveinactive period were used; (2) the first cycle in each stimulation episode was omitted, as this cycle was often very different from the rest; (3) no cycles that began after the end of stimulation were included; and (4) in each stimulation episode, the first $10 \mathrm{sec}$ of cycles meeting the above criteria were used; cycles that began later were omitted from this analysis, as fictive scratching and single-unit activity often become gradually weaker late in the stimulation episode. In a few animals, the VP-HP nerves were never completely inactive; phase analyses of the activity of descending propriospinal neurons recorded in these animals were not performed.

Circular statistics. Following these calculations, the distribution of single-unit mean firing rates within the 10 phases of the nerve activity cycle was characterized using circular statistics (see Mardia, 1972; Batschelet, 1981). Circular statistics have been used previously to characterize rhythmic limb movements (Graham, 1977). The nerve activity cycle was treated as a circle, with $0^{\circ}$ defined as the onset of VP-HP nerve activity and $180^{\circ}$ defined as the offset of VP-HP nerve activity (Figs. 1,2). Each value of single-unit mean firing rate per bin was treated as a vector. Each vector's length was defined as the mean firing rate for a particular bin and each vector's angle was defined as the angle of the center of the bin within the cycle. Thus, the distribution of single-unit mean firing rates within the VP-HP nerve activity cycle was represented hy 10 vectors, one for each of the 10 phases of the cycle. The vector sum of these 10 vectors, normalized to the sum of the mean firing rates, is called the mean vector (see Batschelet, 1981). The mean vector provided a useful summary of the distribution of single-unit activity during the nerve activity cycles. The mean vector length, which can vary from 0 to 1 , indicates the extent to which single-unit activity was concentrated within one portion of each nerve activity cycle. A mean vector length of 0 indicates that the mean firing rate was constant or random; that is, the unit's activity was not related to the nerve activity cycle. A mean vector length of 1 indicates that all the single-unit activity occurred within one bin, the same bin in each cycle. For example, the strongly rhythmic neuron in Figure $1 A$ had a mean vector length of 0.89 ; the very weakly rhythmic neuron in Figure $1 B$ had a mean vector length of 0.08 . The mean vector angle indicates in which phase of the cycle, on average, the unit's activity was concentrated; it is the "center of mass" of the distribution. It varies from $0^{\circ}$ to $360^{\circ}$ (which are equivalent). For example, the neuron in Figure $1 A$ had a mean vector angle of $204^{\circ}$; this means that its activity was concentrated just after the offset of VP-HP aetivity. The use of the mean vector to characterize distributions in which values have been normalized for different bin durations within each cycle has support within the field of statistics of directional data (Mardia, 1972, example 2.4). The description in terms of mean vector length and mean vector angle greatly facilitates the process of comparing distributions of single-unit activity within nerve activity 


\section{A}

\section{Single-unit and Motor Nerve Recordings:}
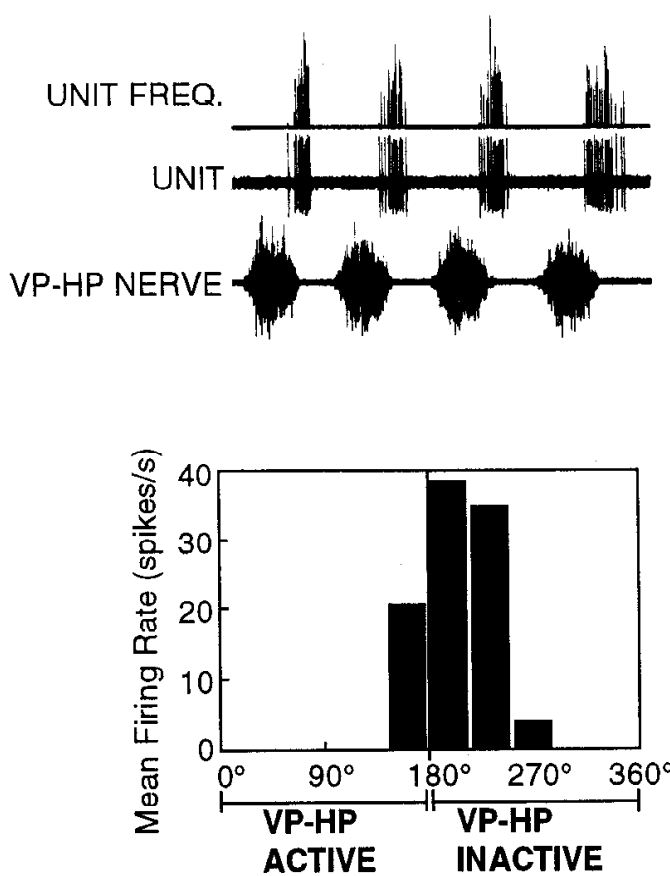

Dual-

Referent

Phase

Histograms:
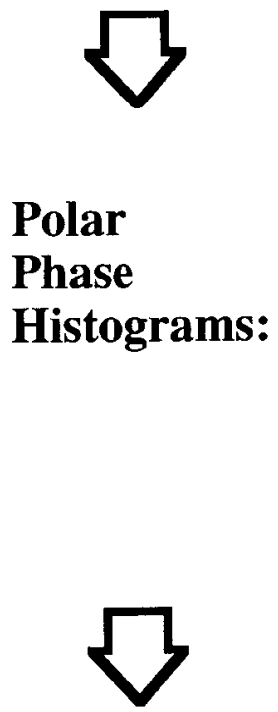

\section{Circular Statistics:}

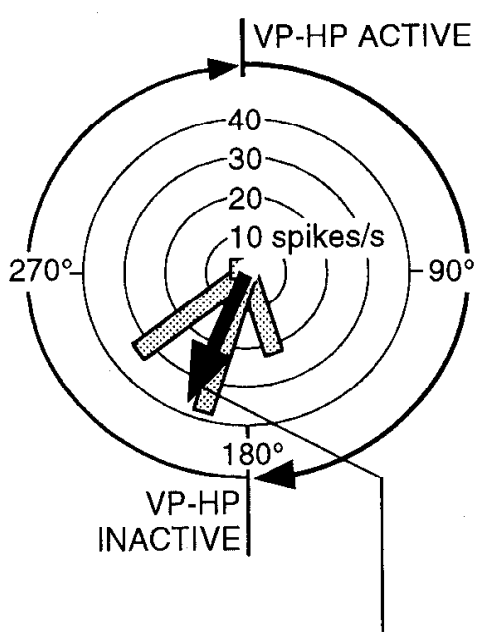

MEAN VECTOR

$$
\begin{aligned}
& \text { Mean Vector Length }=0.89 \\
& \text { Mean Vector Angle }=204^{\circ} \pm 27^{\circ}
\end{aligned}
$$
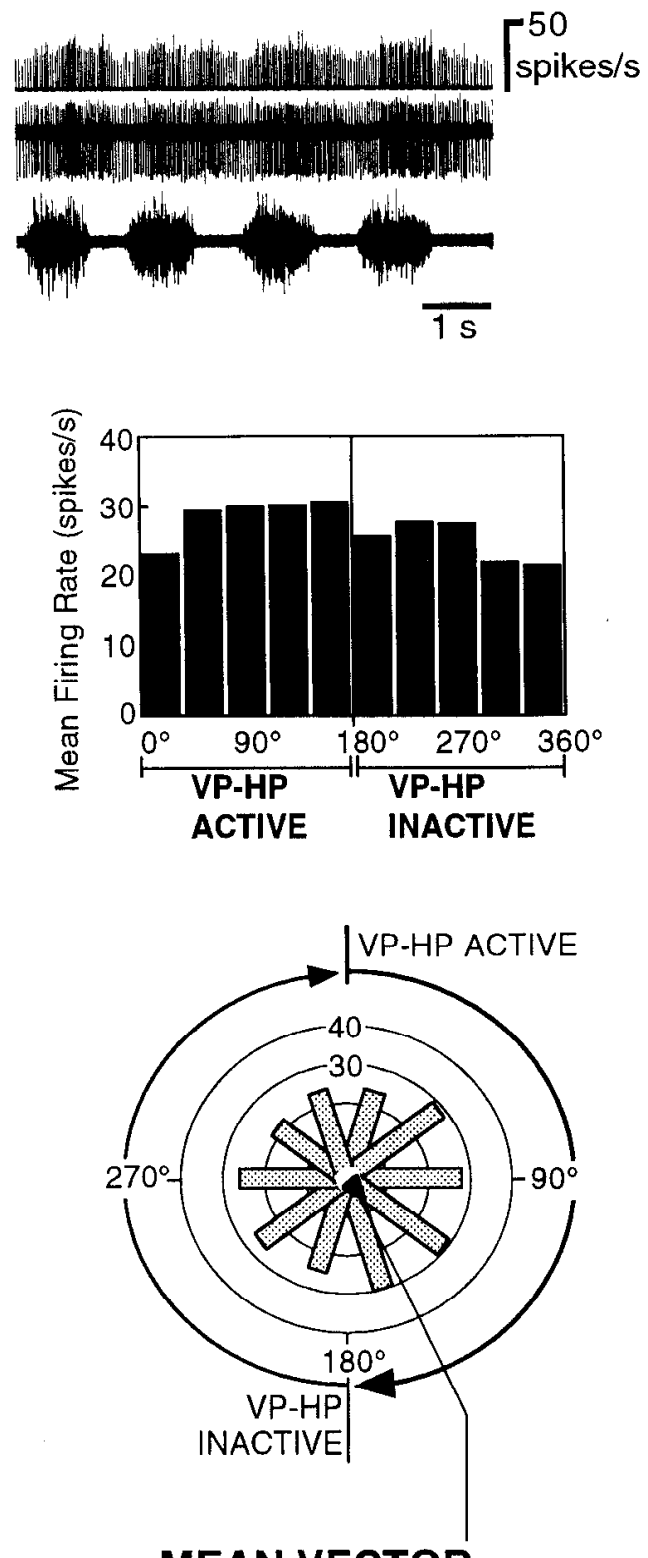

MEAN VECTOR

Mean Vector Length $=0.08$
Mean Vector Angle $=139^{\circ} \pm 78^{\circ}$

Figure 1. Method for phase analysis of propriospinal neuron activity within VP-HP nerve activity cycle during fictive scratching. The transformation of concurrent single-unit and motor-nerve recordings (top row) into dual-referent phase histograms (second row) and descriptive circular statistics (bottom two rows) is illustrated for a very strongly rhythmic neuron $(A)$ and a very wcakly rhythmic neuron $(B)$. See Berkowitz and Stein $(1994 \mathrm{~b})$ for description of recording methods. See Materials and Methods for detailed description of phase analysis method. UNIT FREQ., instantaneous firing rate of recorded unit.

cycles for different sites of stimulation, different types of motor patterns, and different descending propriospinal neurons.

One might obtain a very high value of mean vector length from analysis of a unit's activity within the nerve activity cycle even if only a small amount of data were available. In such a case, the high value of mean vector length could have occurred by chance. On the other hand, a relatively low value of mean vector length obtained from a large amount of data could indicate that a neuron was active with only weak rhythmic modulation, but reliably so. For these reasons, we employed a statistical test, the Rayleigh test (see Mardia, 1972; Graham, 1977; Batschelet, 1981), to evaluate the null hypothesis that the unit's activity was random with respect to the nerve activity cycle, for each site of stimulation. In this test, the number of observations was given by the number of unit spikes contributing to the analysis. For it to be concluded that a unit's activity displayed rhythmic modulation related to fictive scratching, the unit was required to pass the Rayleigh test at the $p<$ 


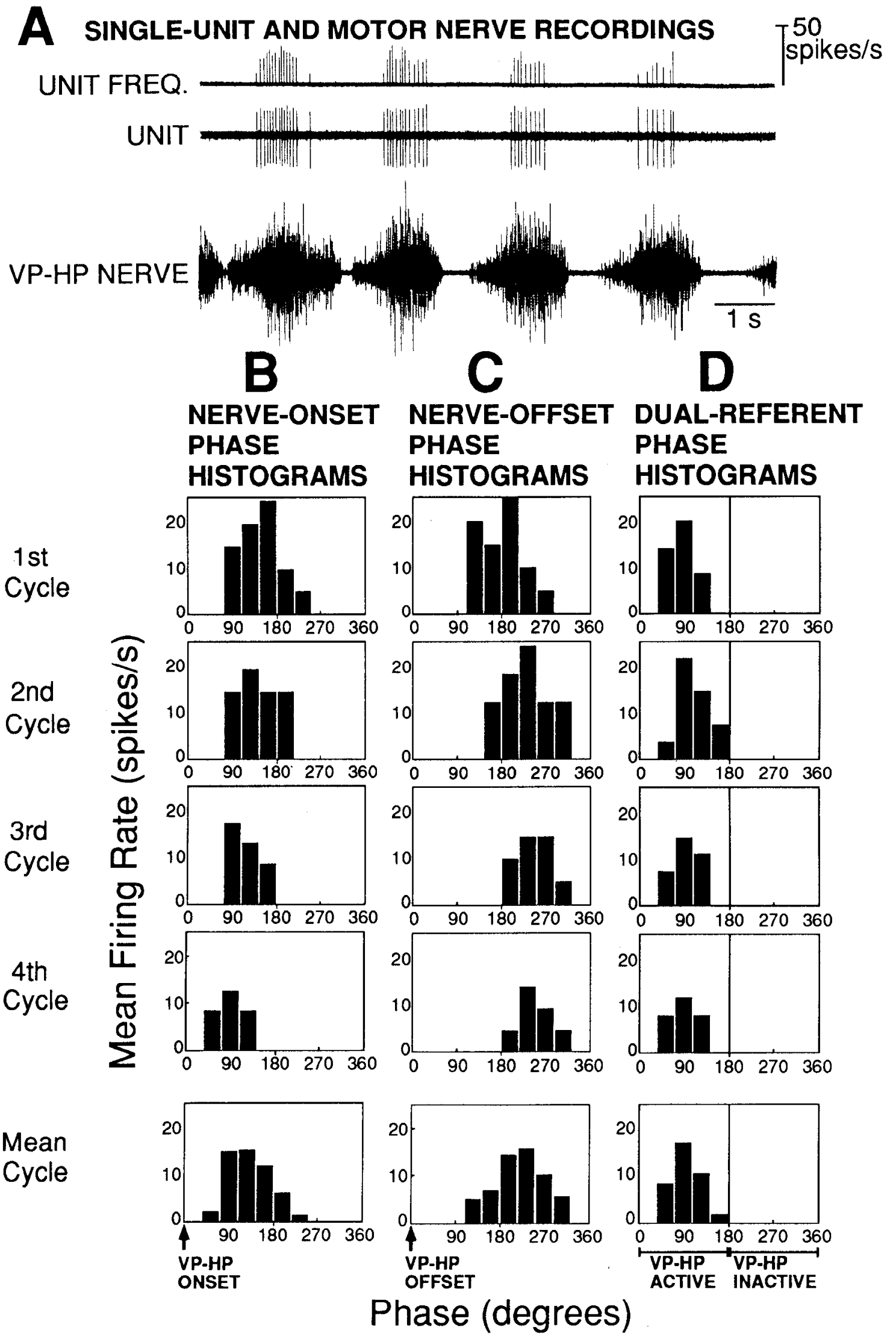

Figure 2. Comparison of methods for phase analysis of single-unit activity within a muscle nerve activity cycle. $A$, Concurrent recordings from a descending propriospinal axon and the ipsilateral VP-HP muscle nerve during four cycles of ipsilateral fictive rostral scratching. See Berkowitz and Stein (1994b) for description of recording methods. $B-D$. Phase analyses of the single-unit activity shown in $A$, using nerve-onset phase histograms $(B)$, nerve-offset phase histograms $(C)$, and dual-rcferent phase histograms $(D)$. Sce Materials and Methods for detailed description of these three methods of analysis. UNIT FREQ., instantaneous firing rate of recorded unit. 
0.01 level, signifying that there was a probability of more than $99 \%$ that the distribution of unit mean firing rates was related to the nerve activity cycle. In addition, the unit mean vector for a given site of stimulation was included in summary graphs only if the data included at least two nerve activity cycles and at least 10 unit spikes.

To facilitate comparison of a unit's activity during fictive rostral scratching and fictive pocket scratching (see Figs. 5, 7), representative unit mean vectors were selected, one each for fictive rostral scratching and fictive pocket scratching. The site along the epidermal shield borders from SP1 to SP3 (for descriptions of sites, see Mortin et al., 1985; Mortin and Stein, 1990; Fig. 1 of Berkowitz and Stein, 1994b) that passed the Rayleigh test with the lowest probability of random unit activity was selected to represent the mean vector for fictive rostral scratching. The site along the shell-skin border from femoral 10 to femoral 3 that passed the Rayleigh test with the lowest probability of random unit activity was selected to represent the mean vector for fictive pocket scratching.

For comparisons of the mean vector length and the mean firing rate of individual units, all available stimulation episodes were used from stimulation sites along the shell-skin borders from anal 5 to femoral 0 and along the epidermal shield borders from SP1 to marginal 5.0 on both sides of the body. Such comparisons were conducted on all units for which sufficient data were available (at least two cycles of fictive scratching and at least 10 unit spikes) from mechanical stimulation of at least four such sites on une side of the body.

Comparison of methods. A more traditional method of characterizing single-unit activity within activity cycles of a nerve involves the use of single-referent phase histograms (Fig. 2). Most commonly, each nerve activity cycle would be defined to begin at the onset of a nerve burst and to end at the onset of the next nerve burst. Then, each such cycle would be divided into equal bins (e.g., 10 equal bins), and the total number of single-unit spikes or the single-unit mean firing rate would be calculated for each of the 10 bins. The graphical results can be called "nerve-onset phase histograms" (Fig. 2B). Alternatively, one could define each nerve activity cycle to begin at the offset of a nerve burst and to end at the offset of the next nerve burst. An analogous process could then be followed to produce "nerve-offset phase histograms" (Fig. 2C). If, instead, one divides each cycle into two parts, the nerve-active period and the nerve-inactive period, and then divides each part into equal bins for calculation of single-unit mean firing rates, one generates dualreferent phase histograms (Fig. $2 D$ ), because both nerve onset and nerve offset are used in the procedure.

To produce either single-referent phase histograms or dual-referent phase histograms that average data from several cycles, one must use different bin widths for different cycles, because the cycle period is not identical for all cycles (i.e., $1 / 10$ of the cycle will be a different amount of time in each cycle). This means that the single-unit mean firing rate in each bin is a more reliable measure than the total number of singleunit spikes in each bin; the latter number is a function of the bin duration. To produce dual-referent phase histograms, one must use different bin widths for the two parts of each cycle. Thus, single-referent phase histograms normalize for cycle period; dual-referent phase histograms normalize both for the duration of the nerve-active period and for the duration of the nerve-inactive period. The proportion of the cycle during which the nerve is active is called the duty cycle. If the duty cycle of the referent nerve were constant, nerve-onset phase histograms and nerve-offset phase histograms would give the same results. In this case, there would be no reason to use dual-referent phase histograms. If, however, the duty cycle varies substantially (e.g., Fig. $2 A$; the VP-HP burst is a much larger fraction of the cycle in the first cycle shown than in the fourth cycle shown), both types of single-referent phase histogram vary substantially from cycle to cycle; in addition, nerve-onset phase histograms give substantially different results from nerve-offset phase histograms (compare Fig. $2 B, C$ ). If, for example, a unit is active in the middle of each nerve burst (e.g., Fig. $2 A$ ), nerveonset phase histograms depict the unit activity as occurring earlier in the cycle whenever the duty cycle is lower (compare Fig. $2 B$, first cycle and fourth cycle). Nerve-offset phase histograms do the reverse (compare Fig. $2 C$, first cycle and fourth cycle). Single-referent phase histograms using the mean values of unit mean firing rate from several nerve cycles depict the unit activity as being less concentrated within the nerve cycle than it actually is (Fig. $2 B, C$, mean cycle). This is because singlereferent phase histograms ignore the actual duration of the nerve burst within each cycle. Thus, if the timing of a neuron's activity is related to the timing of activity in a particular nerve (as the activity of the neuron in Fig. $2 A$ appears to be), single-referent phase histograms are not the best way to assess it. In contrast, dual-referent phase histograms correctly depict the activity of such a unit as occurring in the middle of the nerve burst in each cycle (Fig. $2 D$, first through fourth cycle); dual-referent phase histograms using the mean values of unit mean firing rate from several nerve cycles correctly depict the unit's activity as concentrated in the nerve-active portion of the cycle (Fig. $2 D$, mean cycle).

The duty cycle of the VP-HP nerve (and other hindlimb muscle nerves) does not remain constant in fictive scratching (unpublished observations). Instcad, the duty cycle varies substantially for different forms of fictive scratching, for different sites of stimulation within a single form, and for different cycles within a single episode of fictive scratching (e.g., Fig. $2 A$ ). Duty cycle also varies substantially in other rhythmic behaviors. For example, the duty cycle of the swing phase of stepping in a vertebrate changes dramatically when cycle period changes (see Grillner, 1975). If the activity of each unit recorded were concentrated either at the onset or at the offset of each burst of a particular nerve, one might choose to use nerve-onset phase histograms to describe the activity of the "onset neurons" and nerve-offset phase histograms to describe the activity of the "offset neurons." In our data (see Fig. 5A), individual neurons can have rhythmic activity concentrated in any of several phases of the nerve activity cycle. Thus, dual-referent phase histograms may be a more appropriate method of single-unit phase analysis for rhythmic motor patterns in which duty cycle can vary.

\section{Results}

Phases of unit activity in fictive rostral scratching and fictive pocket scratching

Of 104 tactilely responsive, descending propriospinal axons recorded in the turtle hindlimb enlargement, 58 units $(56 \%)$ were activated during fictive rostral scratching and fictive pocket scratching evoked by stimulation anywhere within the rostral scratch or pocket scratch receptive fields, on at least one side of the body ("motor RF units"; see Berkowitz and Stein, 1994b, for details on unit classification). The activity of 45 of these units $(78 \%)$ showed rhythmic modulation during fictive scratching. The phase of the activity cycle of the ipsilateral hip flexor (VP-HP) muscle nerve in which each unit's activity was concentrated was assessed for all units $(n=13)$ that were rhythmically activated (see Materials and Methods for criteria) during mechanical stimulation of at least four sites on the ipsilateral body surface. The data from four of these units are illustrated in Figure 3. Qualitative examination of the single-unit and VPHP nerve recordings indicated that, for a given site of stimulation, a given unit's activity was concentrated in particular phase of the VP-HP activity cycle, approximately the same phase in every cycle (Fig. $3 A$ ). In addition, the unit's activity was concentrated in approximately the same phase of the VPHP cycle during fictive rostral scratching and fictive pocket scratching (Fig. 3A). In contrast, the unit's activity was concentrated in a different phase of the ipsilateral FT-KE (monoarticular knee extensor muscle) nerve activity cycle during fictive rostral scratching and fictive pocket scratching (Fig. 3A). Quantitative examination with dual-referent phase histograms confirmed that the distribution of single-unit activity with respect to the VP-HP nerve activity cycle was very similar during fictive rostral scratching and fictive pocket scratching (Fig. $3 B$ ). The "preferred phase" of each such distribution can be described by its mean vector angle, with $0^{\circ}$ (or $360^{\circ}$ ) defined as the onset of VP-HP activity and $180^{\circ}$ defined as the offset of VP-HP activity (see Materials and Methods). For the unit shown in Figure 3, $A$ and $B$, the mean vector angle was between $204^{\circ}$ and $251^{\circ}$ for all sites stimulated in the ipsilateral rostral scratch and pocket scratch receptive fields (Fig. $3 C$ ). Thus, this unit's activity was consistently concentrated in the first half of the period of in- 
A Recordings

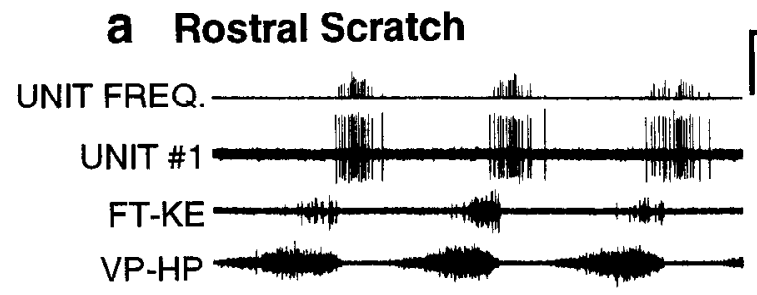

\section{b Pocket Scratch}

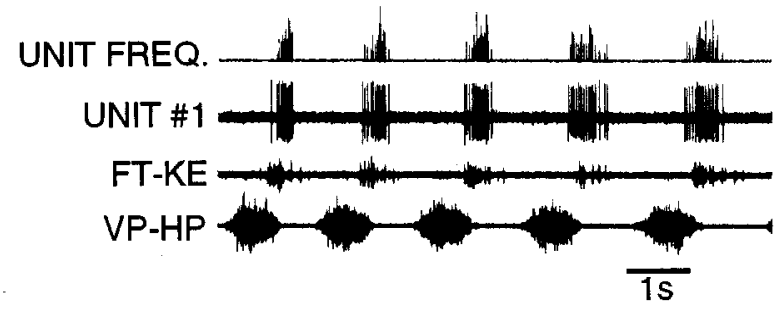

B Phase Histograms

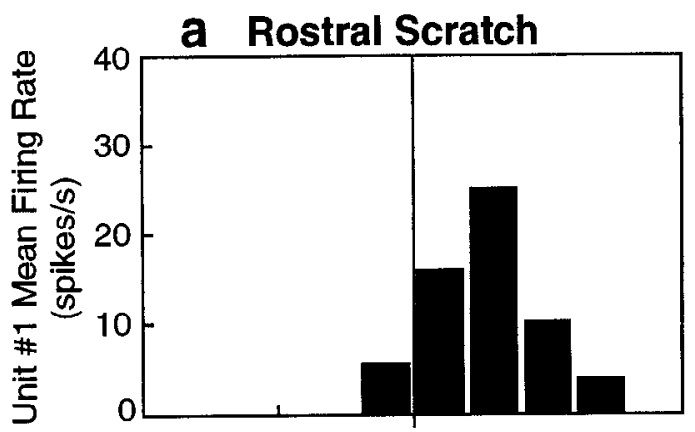

b Pocket Scratch

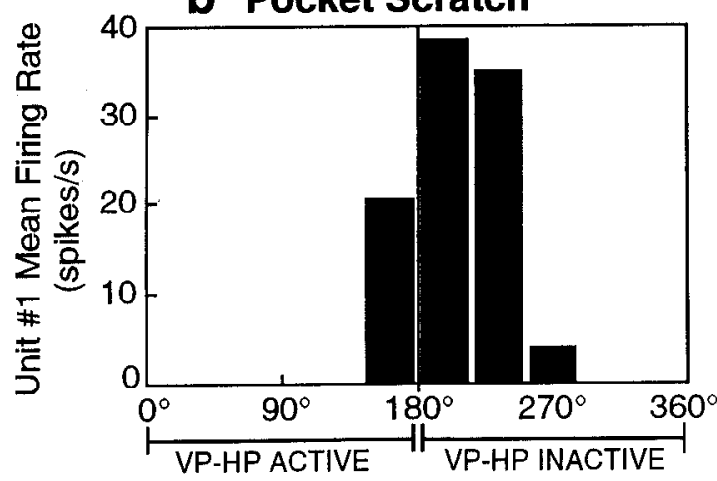

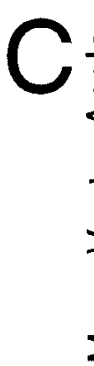

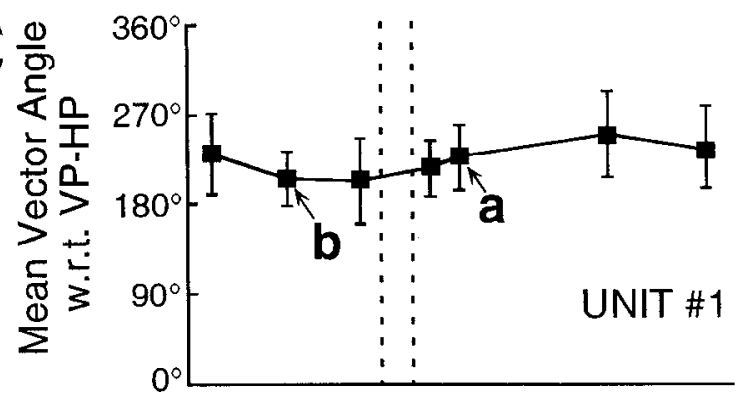

$1)$
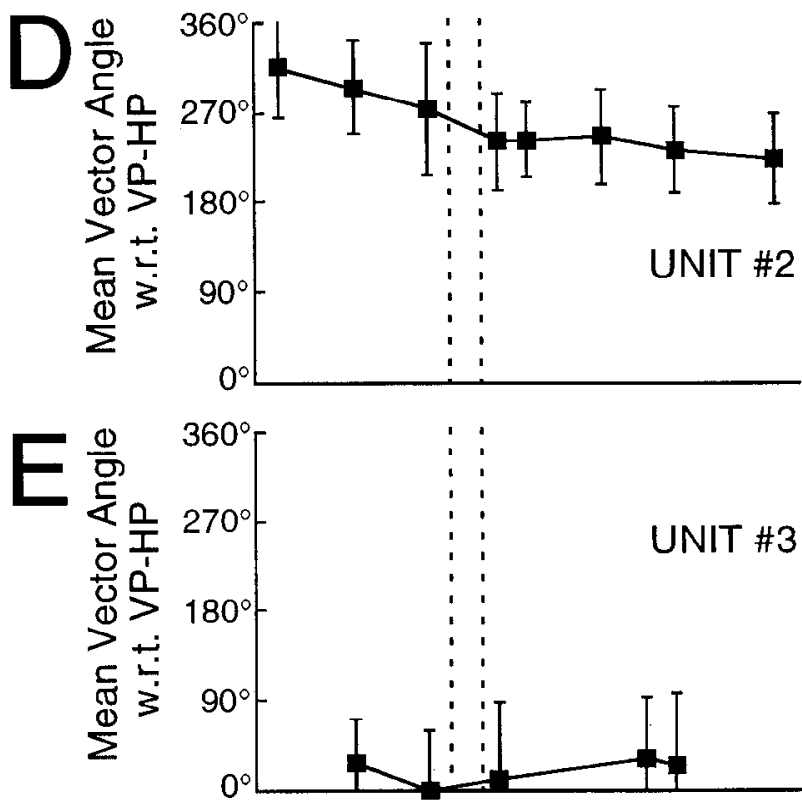

$\mathrm{F}$

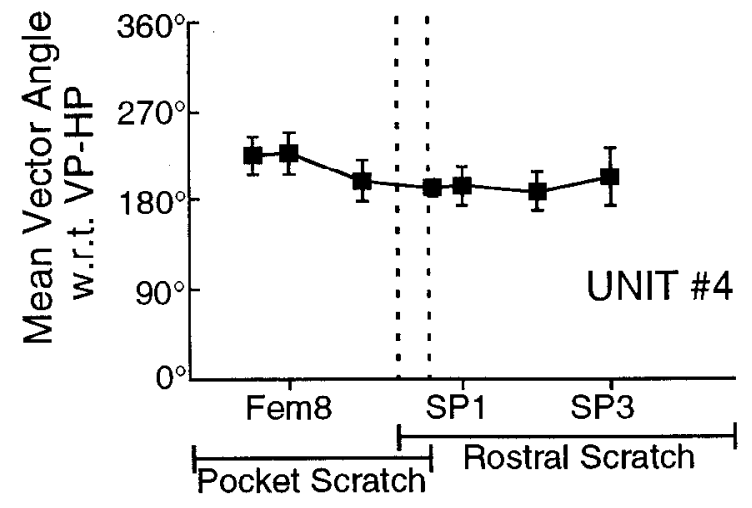

Figure 3. Phases of the ipsilateral VP-HP nerve activity cycle in which single-unit activity was concentrated during tactile stimulation of different sites in the ipsilateral rostral scratch and pocket scratch receptive fields. $A$, Concurrent recordings from a single descending propriospinal axon and the ipsilateral FT-KE (knee extensor) and VP-HP (hip flexor) muscle nerves, during ipsilateral fictive rostral scratching (a) and ipsilateral fictive pocket scratching $(b) . B$, Dual-referent phase histograms of single-unit activity within the ipsilateral VP-HP activity cycle; $B a$ and $B b$ are the phase hislograms for the recordings in $A a$ and $A b$, respectively. $C$, Unit mean vector angles with respect to the ipsilateral VP-HP nerve activity cycle for the unit illustrated in $A$ and $B$, at several sites in the ipsilateral pocket scratch and rostral scratch receptive fields. $C a$ and $C b$ indicate the mean vector angles for the sites stimulated in $A$ and $B, a-b$, respectively. $D-F$, Unit mean vector angles with respect to the ipsilateral VP-HP nerve activity cycle at several sites in the ipsilateral pocket scratch and rostral scratch receptive fields, for three other descending propriospinal units. Error bars in $C-F$ indicate the SEM. See Berkowitz and Stein (1994b) for description of recording methods. See Mortin et al. (1985), Mortin and Stein (1990), and Berkowitz and Stein (1994b, Fig. 1) for description of sites on the body surface. See Materials and Methods for explanation of mean vector angle. UNIT FREQ., instantaneous firing rate of recorded unit; w.r.t., with respect to.

activity of the ipsilateral VP-HP nerve, whether fictive rostral scratching or fictive pocket scratching was evoked. Each of several other units had a different preferred phase and each unit's preferred phase remained relatively constant for all sites stim- ulated in the ipsilateral rostral scratch and pocket scratch receptive fields (Fig. $3 D-F$ ). Figure $3 D$ shows an example of a unit with a preferred phase that changed gradually across the pocket scratch and rostral scratch receptive fields. This unit's 
A

\section{ROSTRAL SCRATCH:}

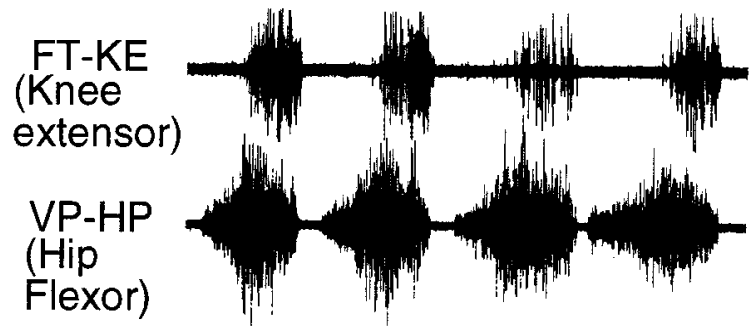

B

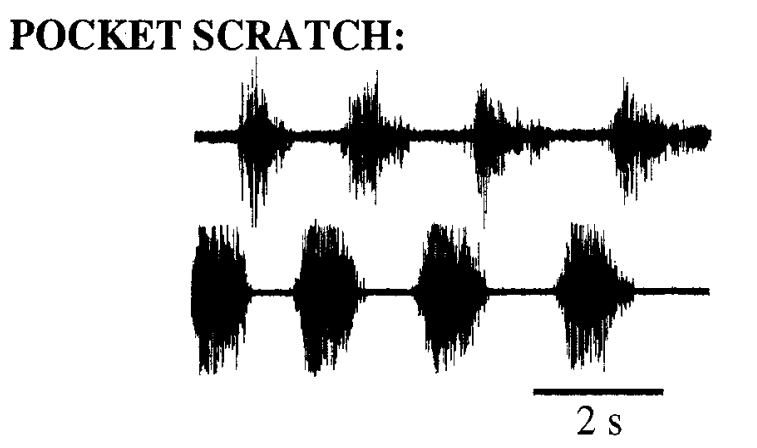

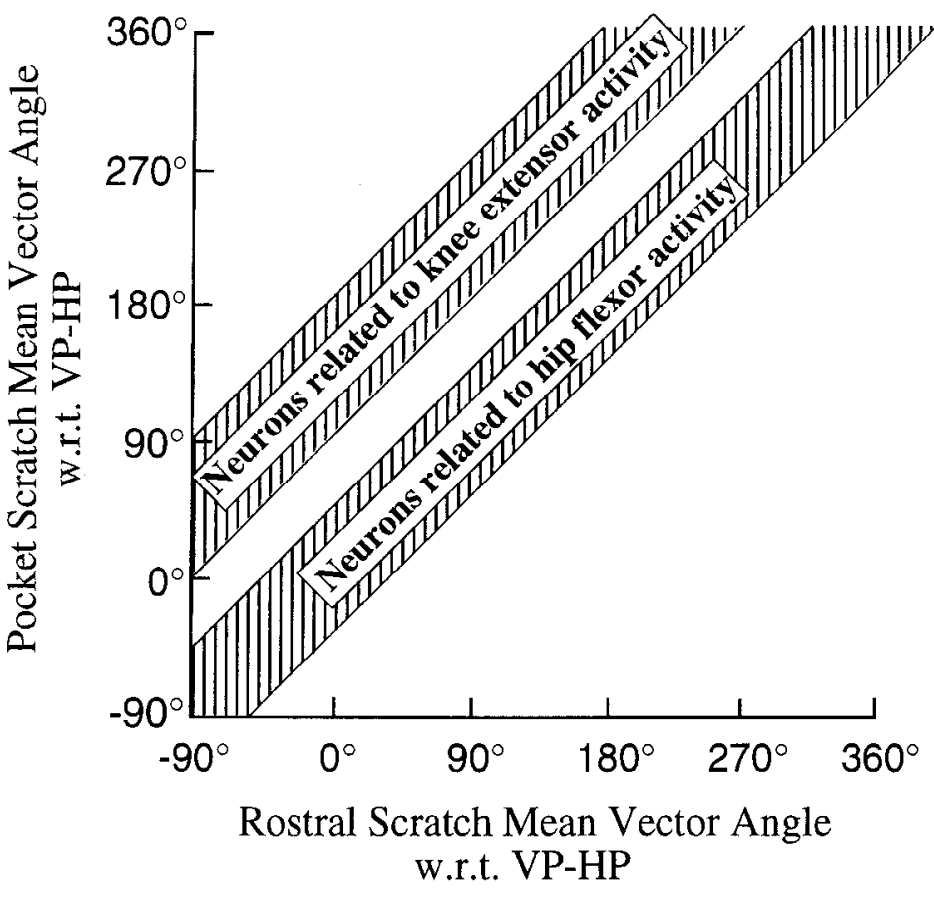

Figure 4. Expected phase delay of activity in knee control-related neurons during fictive pocket scratching as compared to fictive rostral scratching. $A$ and $B$, Examples of relative timing of FT-KE (monoarticular knee extensor) muscle nerve bursts and VP-HP (hip flexor) muscle nerve bursts during fictive rostral scratching $(A)$ and fictive pocket scratching $(B)$ in a turtle with the D3-D9 spinal segments intact. $C$, Expected relationship between unit mean vector angles with respect to ipsilateral VP-HP during ipsilateral fictive pocket scratching and ipsilateral fictive rostral scratching, for units involved in knee control and units involved in hip control. w.r.t., with respect to.

phase shift was one of the largest of the units studied. The site (Fem8) in the pocket scratch receptive field that evoked the most clearly rhythmic activity (i.e., the unit's activity had the highest probability of being related to the nerve activity cycle by the Rayleigh test) had a mean vector angle of $295^{\circ}$; the site (SP2) in the rostral scratch receptive field that evoked the most clearly rhythmic activity had a mean vector angle of $247^{\circ}$, yielding a phase shift of $48^{\circ}$ between fictive rostral scratching and fictive pocket scratching (see Fig. 5).

Fictive rostral scratching and fictive pocket scratching are primarily distinguished by the relative timing of the FT-KE (knee extensor) nerve burst and the VP-HP (hip flexor) nerve burst (Fig. 4A,B; see also Mortin et al., 1985; Robertson et al., 1985). In rostral scratching, each FT-KE burst begins during the VP-HP burst and ends at the same time as the VP-HP burst ends (Fig. $4 A$ ). In pocket scratching, each FT-KE burst begins near the end of the VP-HP burst and continues through the period when VP-HP is inactive (Fig. $4 B$ ). Thus, the timing of the FT-KE burst with respect to the VP-HP activity cycle is phasc dclayed about $90-180^{\circ}$ in pocket scratching as compared to rostral scratching. If the timing of a propriospinal neuron's activity were always related to the control of hip movement, its mean vector angle with respect to VP-HP (a hip flexor) would be expected to remain constant. If such a propriospinal neuron were rhythmically active during both fictive rostral scratching and fictive pocket scratching, it would be expected to have the same mean vector angle with respect to VP-HP during both forms of fictive scratching (Fig. 4C). If, on the other hand, the timing of a propriospinal neuron's activity were always related to control of knee movement, it would be expected to have different mean vector angles with respect to VP-HP, depending on whether fictive rostral scratching or fictive pocket scratching were evoked. Specifically, its mean vector angle with respect to VP-HP would be phase delayed $90-180^{\circ}$ in fictive pocket scratching as compared to fictive rostral scratching (Fig. 4C).

The actual mean vector angles of descending propriospinal neurons in fictive pocket scratching as compared to fictive rostral scratching are shown in Figure $5 \mathrm{~A}$. This comparison includes all rhythmic motor RF units for which such an analysis could be done (see Materials and Methods). For all but one unit, the unit's mean vector angle with respect to VP-HP was approximately the same for the two forms of fictive scratching (Fig. 5). The correlation coefficient was 0.94 . This analysis suggests that the timing of activity in nearly all descending propriospinal neurons recorded was closely related to hip control and was not closely related to knee control.

\section{Phases of unit activity in ipsilateral and contralateral fictive scratching}

Of 51 tactilely responsive descending propriospinal axons recorded on the right side during stimulation of either side of the body, $18(35 \%)$ were rhythmically excited by stimulation of either side [i.e., a mean vector calculated with respect to the right (ipsilateral) VP-HP nerve during ipsilateral fictive scratching and a mean vector calculated with respect to the left (contralateral) VP-HP nerve during contralateral fictive scratching both passed the Rayleigh test with $p<0.01$; see Materials and Methods]. When fictive scratching was evoked on one side, the VP-HP nerve on the opposite side was weakly activated, usually in bursts that were out of phase with the stronger VP-HP bursts 

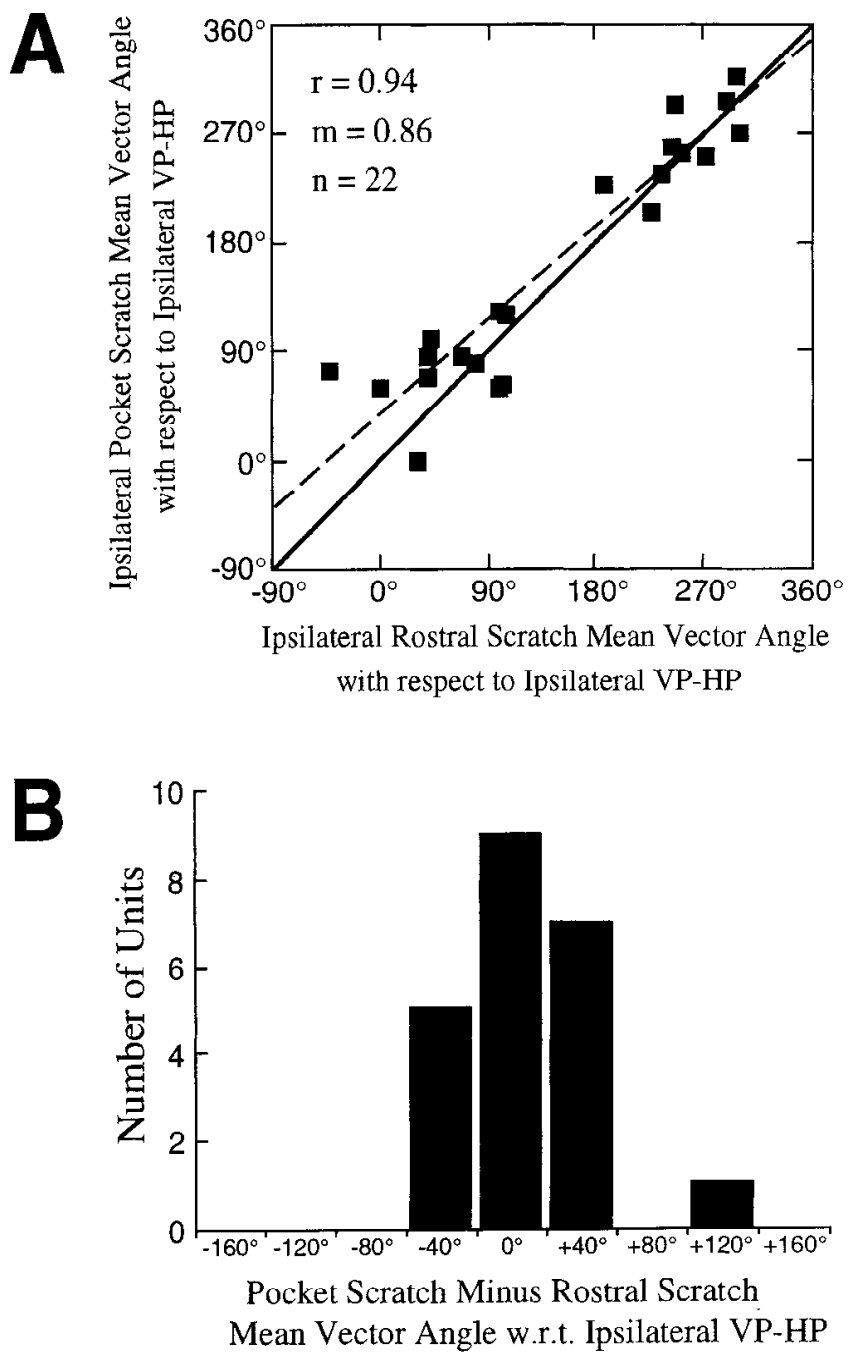

Figure 5. Actual relationship between unit mean vector angles with respect to the ipsilateral VP-HP nerve activity cycle during ipsilateral fictive rostral scratching and ipsilateral fictive pocket scratching, for all rhythmic motor RF units for which sufficient data were available. $A$, Comparison of representative fictive pocket scratch and fictive rostral scratch mean vector angles for all units. The solid line is $\mathrm{y}=\mathrm{x}$; the dashed line is the best linear fit to the data. $r$, correlation coefficient of best line; $m$. slope of best line; $n$, number of units contributing to this analysis. $B$, Histogram showing the distribution of differences between fictive pocket scratch mean vector angle and fictive rostral scratch mean vector angle, for units shown in $A$. Each value on the $\mathrm{x}$-axis represents the midpoint of a $40^{\circ}$ range. See Materials and Methods for description of data selection rules. w.r.t., with respect to.

on the stimulated side (Fig. 6; see also Berkowitz and Stein, 1994b). Qualitative examination of the activity of bilaterally responsive neurons suggested that most units that were activated in a particular phase of the ipsilateral VP-HP nerve activity cycle during ipsilateral fictive scratching were activated in a similar phase of the ipsilateral VP-HP nerve activity cycle during contralateral fictive scratching (e.g., Fig. $6 A a, A b$ ). For a few such units, the weak ipsilateral VP-HP bursts evoked during contralateral fictive scratching had sufficiently clear onsets and offsets to form the basis of a quantitative single-unit phase analysis. In these cases, the unit mean vector angles with respect to ipsilateral VP-HP were approximately the same in ipsilateral and contralateral fictive scratching (e.g., Fig. $6 \mathrm{Ac}$ ). Qualitative examination suggested that some other units were rhythmically activated in a very different phase of the ipsilateral VP-HP nerve activity cycle during ipsilateral and contralateral fictive scratching (e.g., Fig. $6 B a, B b$ ). Whenever the quantitative phase analysis could be conducted for these units, the unit mean vector angles with respect to ipsilateral VP-HP were substantially different in ipsilateral and contralateral fictive scratching (Fig. $6 B c$ ). This was true despite the fact that the unit mean vector angles were approximately the same during fictive rostral scratching and fictive pocket scratching evoked on a single side (Fig. $6 B C$ ).

\section{Strengths of rhythmic modulation of unit activity}

The activity of the descending propriospinal neurons recorded displayed a wide range of strengths of rhythmic modulation during fictive scratching. The strength of rhythmic modulation of a unit's activity with respect to a nerve activity cycle can be described by the unit's mean vector length, which can vary from 0 to 1 (see Materials and Methods). A mean vector length of 0 indicates that the unit's activity was random with respect to the nerve's activity; a mean vector length of 1 indicates that all the unit's activity occurred in the same phase of the nerve activity cycle. Unit mean vector lengths, with respect to the VP-HP nerve on the same side as fictive scratching was evoked, are shown in Figure 7 for all motor RF units recorded for which sufficient data were available (see Materials and Methods). For some neurons, the mean vector length was nearly 0 or nearly 1 , but for most neurons, it was between 0.2 and 0.8 . Thus, there may be a continuous distribution of strengths of rhythmic modulation among descending propriospinal neurons during fictive scratching.

An individual unit could show very different degrees of rhythmic modulation during stimulation of different sites, just as a unit could be active with very different firing rates during stimulation of different sites (see Fig. 9 of Berkowitz and Stein, 1994b). Some units clearly showed stronger rhythmic modulation whenever they generated spikes at a lower rate (Fig. $8 A$ ). When the relationship between unit mean vector length and unit mean firing rate was examined for all sites of stimulation for four such units (see Berkowitz and Stein, 1994b, for mean firing rate calculation methods), the unit's mean firing rate was negatively correlated with the unit's mean vector length in all four cases (Fig. $8 B-E$ ). The relationship between unit mean vector length and unit mean firing rate was examined for all units for which sufficient data were available (see Materials and Methods). The unit's mean firing rate was negatively correlated with the unit's mean vector length in 9 of the 10 units. The correlation coefficients for all 10 units ranged from +0.18 to -0.98 , with a mean of -0.57 and a standard deviation of 0.36 .

\section{Discussion}

Phases of unit activity in fictive rostral scratching and fictive pocket scratching

Many tactilely responsive descending propriospinal axons recorded in the turtle hindlimb enlargement were rhythmically excited by stimulation anywhere within the rostral scratch or pocket scratch receptive fields on at least one side of the body (Berkowitz and Stein, 1994b). Phase analyses of single-unit activity during fictive scralching have now shown that each such neuron was activated in a particular phase of the activity cycle of hip flexor (VP-HP) motoneurons during stimulation of a variety of sites on one side of the body. In fact, for nearly all such neurons, the neuron was activated during fictive rostral scratching in approximately the same phase of the VP-HP ac- 
A

\section{a Ipsilateral Rostral Scratch}

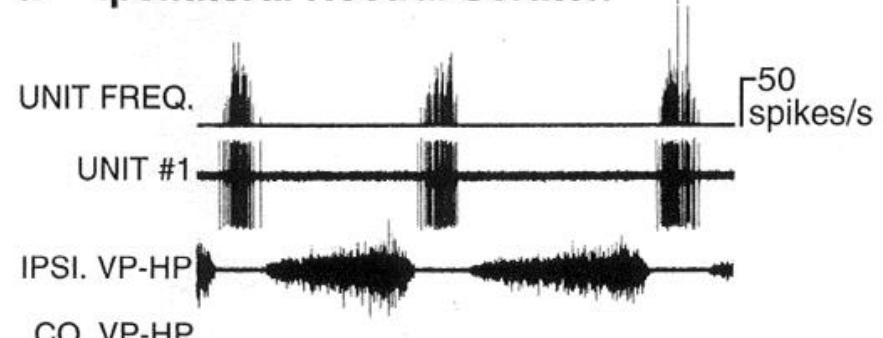

CO. VP-HP

\section{b Contralateral Rostral Scratch}
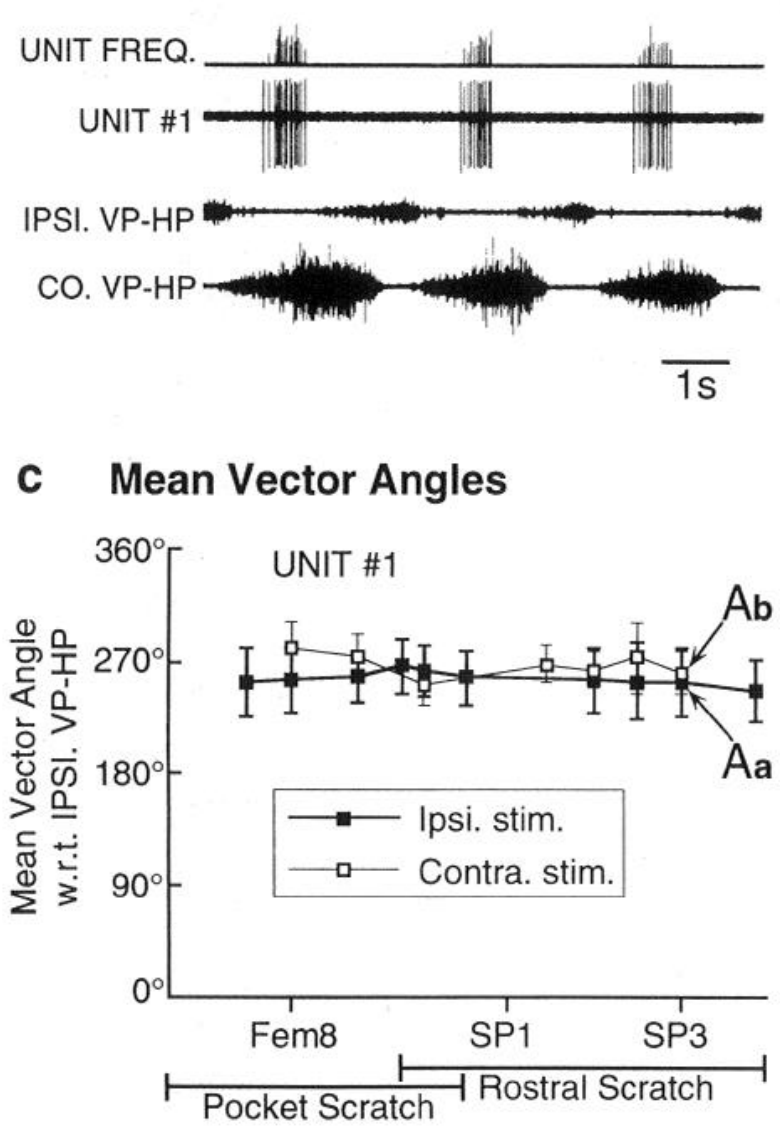

a Ipsilateral Rostral Scratch

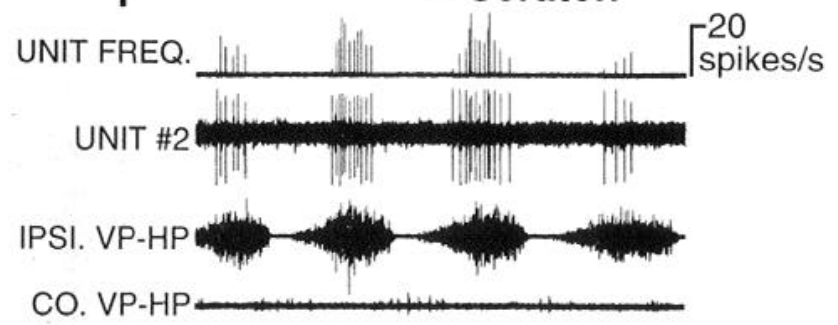

b Contralateral Rostral Scratch

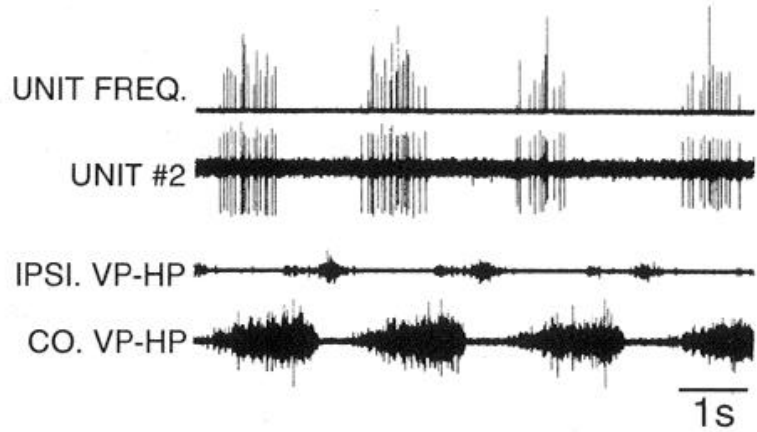

C Mean Vector Angles

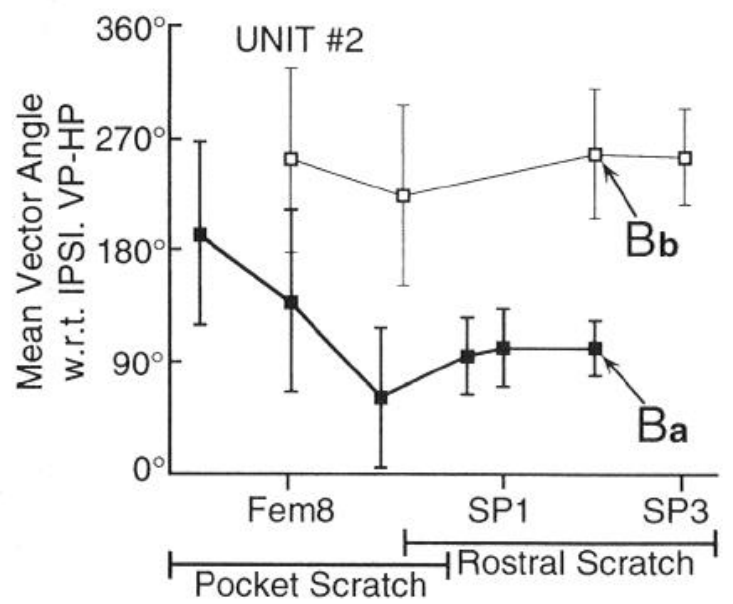

Figure 6. Phases of single-unit activity in the ipsilateral VP-HP nerve activity cycle during ipsilateral and contralateral fictive scratching. $a$ and $b$ in $A$ and $B$ are examples of concurrent recordings from a descending propriospinal axon, the ipsilateral VP-HP muscle nerve, and the contralateral VP-HP muscle nerve, during ipsilateral $(a)$ and contralateral $(b)$ fictive rostral scratching. $A, \mathrm{~A}$ unit that was active in a similar phase of the ipsilateral VP-HP nerve activity cycle during fictive scratching evoked on either side of the body. $B$, A unit that was active in very different phases of the ipsilateral VP-HP nerve activity cycle during ipsilateral and contralateral fictive scratching. Ipsilateral and contralateral SP 3 were the sites stimulated in $A a$ and $A b$, respectively. Ipsilateral and contralateral SP2 were the sites stimulated in $B a$ and $B b$, respectively. $A c$ and $B c$, Unit mean vector angles for all sites stimulated on both sides of the body, for the units illustrated in $A a, A b, B a$, and $B b$, respectively. $\mathbf{\square}$, ipsilateral stimulation; $\square$, contralateral stimulation. Points labeled $A a, A b, B a$ and $B b$ indicate the sites stimulated in $A a, A b, B a$, and $B b$, respectively. Error bars indicate the SEM. UNIT FREQ., instantaneous firing rate of the recorded unit; IPSI. VP-HP, ipsilateral VP-HP muscle nerve; CO. VP-HP, contralateral VP-HP muscle nerve; Ipsi. stim., ipsilateral stimulation; Contra. stim., contralateral stimulation; w.r.t., with respect to.

tivity cycle in which it was activated during fictive pocket scratching. We did not demonstrate directly that these neurons contributed to generation of motor activity. It is likely, however, that some of the descending propriospinal neurons recorded contributed to the generation of scratch motor rhythms. Since many of these neurons were rhythmically activated during both forms of fictive scratching, some may contribute to generation of both rostral scratch and pocket scratch motor patterns.

This evidence supports the hypothesis that individual vertebrate CNS neurons can contribute to generation of multiple motor patterns or behaviors. Studies in other vertebrate species and systems have also supported this hypothesis. Rhythmic 

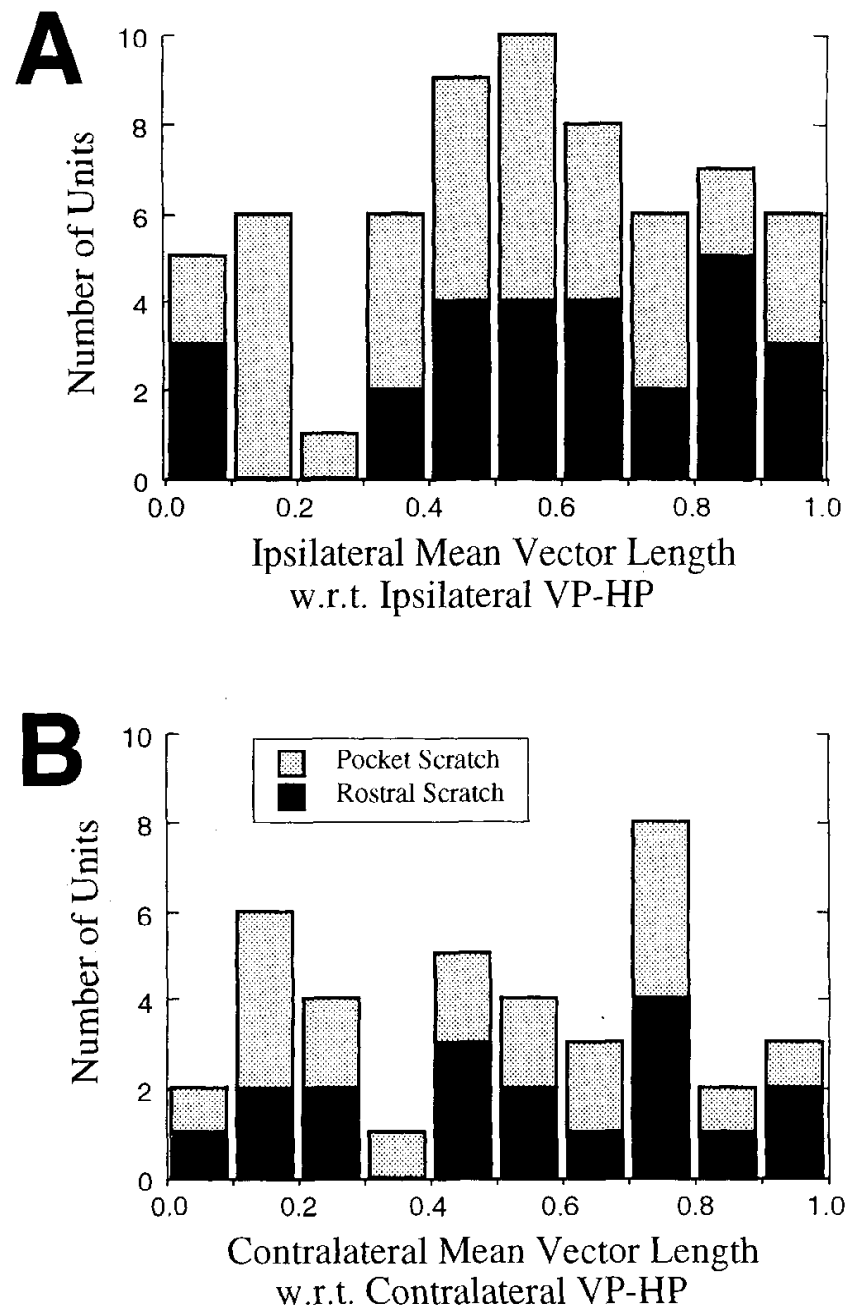

Figure 7. Histograms showing distributions of unit mean vector lengths with respect to the VP-HP muscle nerve on the side of stimulation, for ipsilateral $(A)$ and contralateral $(B)$ fictive scratching. Representative rostral scratch unit mean vector lengths are shown in black; representative pocket scratch unit mean vector lengths are shown in gray. All motor RF units for which sufficient data were available $(n=42)$ were used in this analysis; for some of these neurons, sufficient data were available only for a subset of the four types of fictive scratching (rostral and pocket scratching, ipsilaterally and contralaterally). See Materials and Methods for explanation of mean vector length and description of data selection rules. w.r.t., with respect to.

activity has been recorded from individual spinal premotor interneurons during both fictive swimming and fictive struggling in embryonic tadpoles (Soffe et al., 1984; Soffe, 1993). Individual cervical propriospinal neurons in the cat have been shown to be rhythmically active during fictive respiration, in addition to fictive vomiting, fictive coughing, or fictive swallowing (Nonaka and Miller, 1991; Grelot et al., 1993). Rhythmic activity has also been recorded from la inhibitory interneurons, ventral spinocerebellar tract neurons, and Renshaw cells in the cat spinal cord during actual or fictive scratching (Arshavsky et al., 1978; Deliagina and Orlovsky, 1980; Deliagina and Feldman, 1981) and actual or fictive locomotion (Arshavsky et al., 1972; Feldman and Orlovsky, 1975; Pratt and Jordan, 1987), although scratching and locomotion were elicited during different recordings. Individual unidentified spinal interneurons have also been shown to be rhythmically active during fictive scratching and "slow oscillations" (perhaps fictive stepping) in cats (Ber- kinblit et al., 1978b). If many CNS neurons are rhythmically activated during two rhythmic behaviors, it seems likely that some of them contribute to generation of both behaviors. Thus, this combination of studies builds the case that the sets of CNS neurons used in generation of different vertebrate behaviors may be largely overlapping, as has been shown for several invertebrate behaviors (see Getting and Dekin, 1985; Dickinson and Moulins, 1992; Kristan et al., 1992; Marder and Weimann, 1992; Heinzel et al., 1993; Pearson, 1993).

For most descending propriospinal neurons, during stimulation of one side of the body, the neuron was activated during fictive rostral scratching in a phase of a hip muscle nerve's activity cycle that was similar to its phase during fictive pocket scratching. Fictive rostral scratching and fictive pocket scratching are primarily distinguished by the relative timing of knee extensor muscle nerve bursts and hip flexor muscle nerve bursts (Fig. 4; see also Robertson et al., 1985). One might have expected that similar proportions of descending propriospinal neurons would be activated with hip muscle nerve-related timing and knee muscle nerve-related timing. Instead, the timing of activity in all but one of the rhythmically modulated neurons tested was closely related to the activity cycle of a hip flexor muscle nerve. There are at least two possible explanations for this finding. One explanation is that many knee control-related propriospinal neurons exist, but do not have descending axons in the region from which recordings were obtained. Instead, they may have (1) only local axons that do not leave the gray matter, (2) only ascending funicular axons, (3) descending funicular axons that terminate rostral to the caudal D9 segment, or (4) descending axons in the ventral funiculus or the ventral-most lateral funiculus. An alternate explanation is that the turtle spinal cord is able to generate the appropriate knee-hip synergies for fictive rostral scratching and fictive pocket scratching without requiring knee control-related propriospinal neurons.

The possibility that one set of spinal neurons with hip controlrelated rhythmic activity could create the appropriate knee-hip synergies for both rostral scratching and pocket scratching was examined by considering models for the selection and generation of rostral scratch and pocket scratch motor patterns (Fig. 9). In a very simple model (Fig. 9A), some spinal neurons might be activated by tactile stimulation throughout the rostral scratch receptive field and not activated at all by stimulation in the pocket scratch receptive field. These neurons would then activate a set of spinal neurons that generates a rostral scratch motor pattern. An entirely different set of spinal neurons would be activated by tactile stimulation in the pocket scratch receptive field and would itself activate a separate set of pocket scratchgenerating spinal neurons. The data presented in the preceding companion article (Berkowitz and Stein, 1994b) and this article are inconsistent with such a model on two counts. First, the descending propriospinal neurons recorded had tactile excitatory receptive fields that did not match either the rostral scratch or the pocket scratch receptive field. Most such neurons were excited by tactile stimulation in both the rostral scratch receptive field and the pocket scratch receptive field, but were broadly tuned to a particular region of the body surface (Fig. 9 of Berkowitz and Stein, 1994b). This observation suggests that the two populations of neurons responsible for selection of these two forms of scratching may be largely overlapping. Second, many such neurons were rhythmically activated during both fictive rostral scratching and fictive pocket scratching. This finding suggests that the two populations of neurons responsible for 


\section{A RECORDINGS}
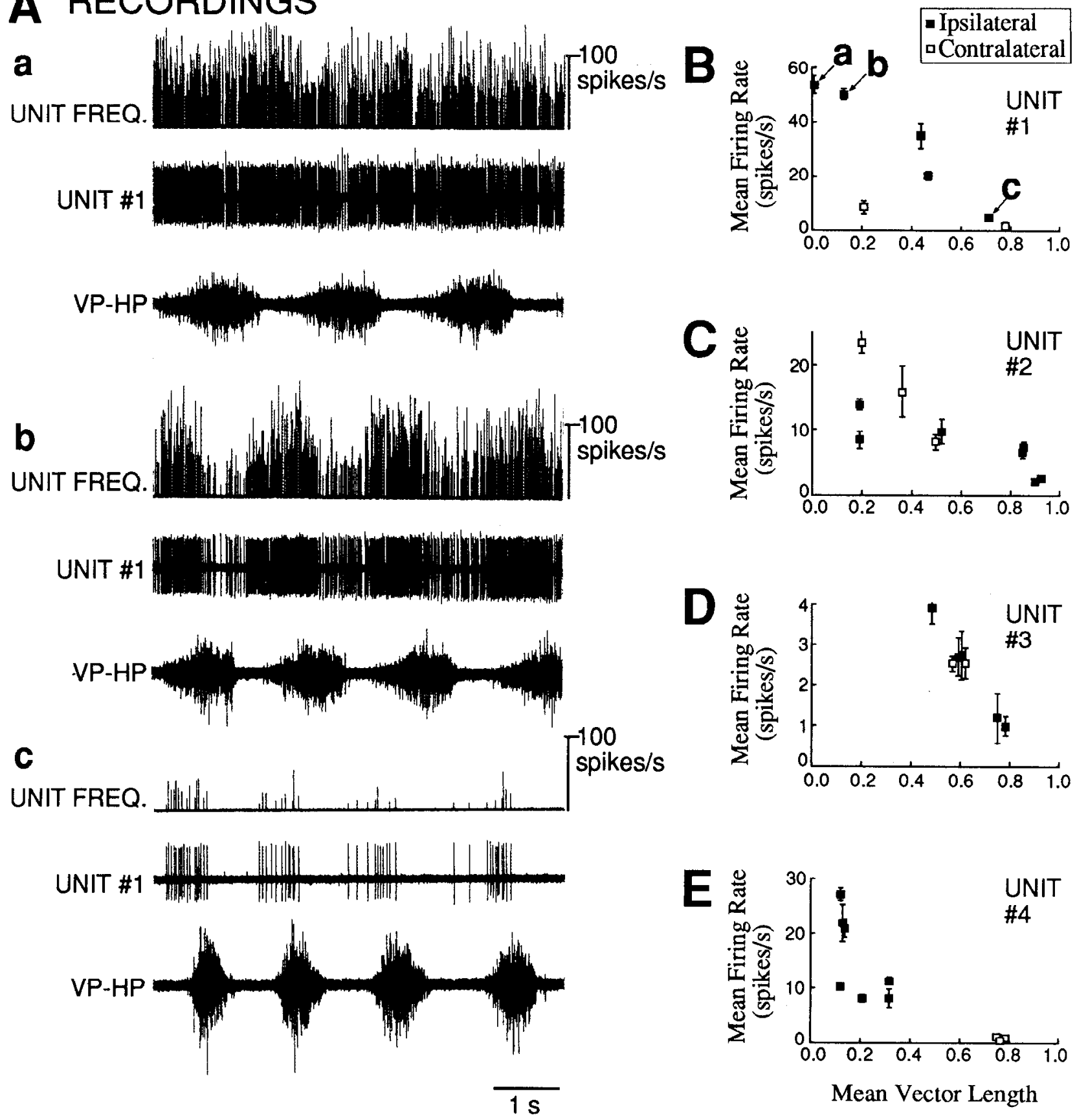

Figure 8. Relationship between a unit's mean firing rate and the strength of rhythmic modulation of the unit's activity for different sites of stimulation. $A$, Concurrent recordings of a descending propriospinal axon and the ipsilateral VP-HP muscle nerve, showing the association between lower unit firing rates and stronger rhythmic modulation of the unit's activity, for three stimulation sites: $a, \mathrm{SP} 2 ; b$, femoral $0 ; c$, femoral 8 . $U N I T$ $F K E Q$.. instantaneous firing rate of recorded unit. $B$, Relationship between unit mean firing rate and unit mean vector length at all sites of stimulation, for the unit shown in $A$; points labeled $a-c$ indicate the values for the sites stimulated in $A a-A C$, respectively. $\mathbf{E}$, ipsilateral sites; $\square$, contralateral sites. The correlation coefficient was -0.80 . $C-E$, Relationship between unit mean firing rate and unit mean vector length at all sites of stimulation, for three other descending propriospinal neurons. The correlation coefficients for $C, D$, and $E$, respectively, were -0.77 , -0.98 , and -0.84 . Error bars in $B-E$ indicate the SEM. See Berkowitz and Stein (1994b) for description of mean firing rate calculation.

generation of these two forms of scratching also may be largely overlapping. In fact, since the same recorded neurons were broadly tuned to regions of the body surface and were rhythmically activated during the two forms of fictive scratching, single propriospinal neurons may contribute to both selection and generation of both rostral scratching and pocket scratching.

The model illustrated in. Figure $9 B$ incorporates both of these findings and shows how hip control-related neurons alone could create appropriate knee-hip synergies during these two forms of fictive scratching. The key elements of this model are four sets of propriospinal neurons: "excitatory pocket scratch neurons" (EPs), "inhibitory pocket scratch neurons" (IPs), "excitatory rostral scratch neurons" (ERs), and "inhibitory rostral scratch neurons" (IRs). (The model also includes several sets of 

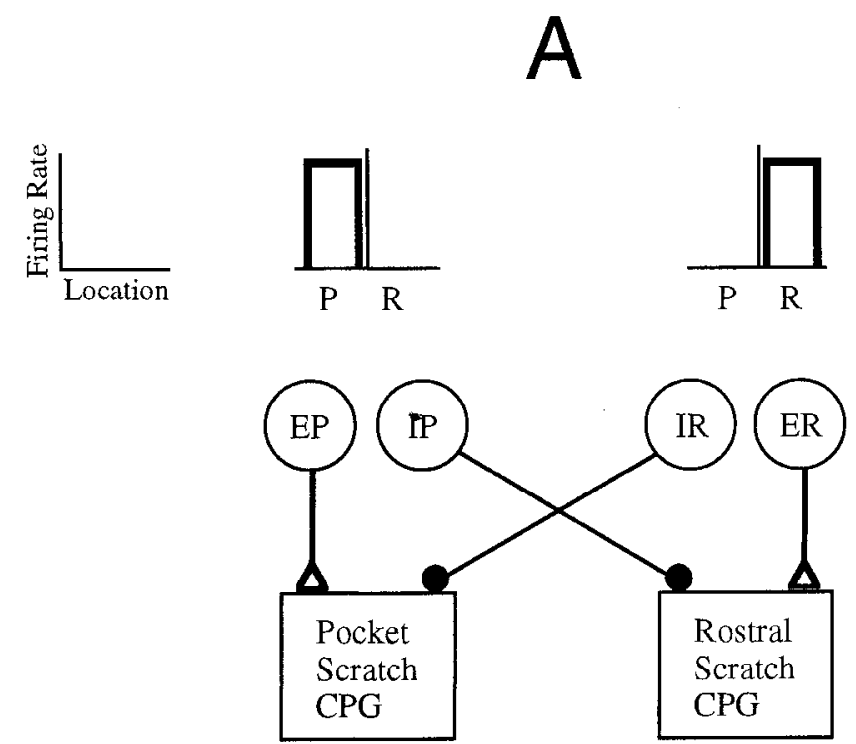
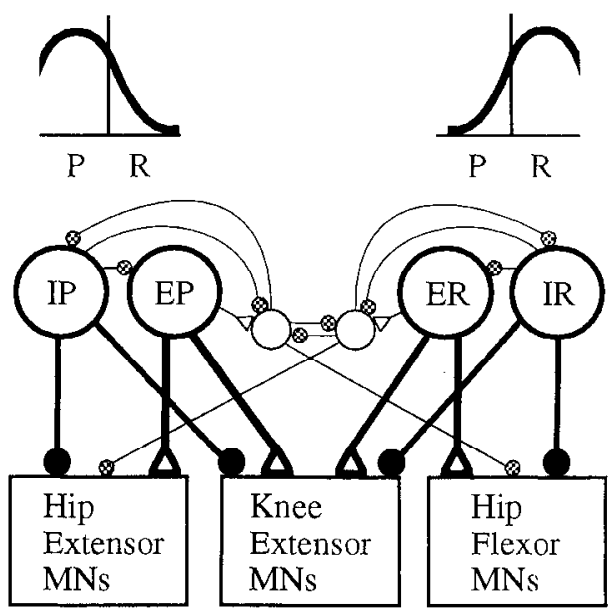

Figure 9. Two alternative models for the selection and generation of rostral scratching and pocket scratching by neural circuitry in the turtle spinal cord. $A$. A model involving completely separate populations of spinal neurons for selection of rostral scratching and pocket scratching, as well as separate populations of spinal neurons for generation of these two forms of scratching. The data are not consistent with this model. $B$, A model involving overlapping populations of spinal neurons that are broadly tuned to regions of the body surface. Each neuron contributes to some degree to selection and generation of each motor pattern. Each neuron projects, directly or indirectly, to both hip muscle and knee muscle motoneurons. The data in the preceding companion article (Berkowitz and Stein, 1994b) and the present data appear to be consistent with this model. The top row in each model depicts the firing rates of the neurons represented in the row immediately below, as a function of site on the body surface. Output connections of these neurons are represented in the bottom row. $\triangle$, excitatory synaptic connections; inhibitory synaptic connections. See Discussion for detailed comparison of the data to these models. $C P G$, central pattern generator; $M N s$, motoneurons.

propriospinal neurons that provide reciprocal inhibition of antagonists; these will not be discussed.) Each EP and each IP is broadly tuned to a region of the pocket scratch receptive field. Each EP and each IP projects to both knee extensor and hip extensor motoneurons (either monosynaptically or polysynaptically). EPs produce excitation in both knee extensor and hip extensor motoneurons; IPs produce inhibition in both knee extensor and hip extensor motoneurons; EPs and IPs burst alternately because each set inhibits the other (either monosynaptically or polysynaptically). Activity in EPs leads to synchronous excitation of knee extensor and hip extensor motoneurons; activity in IPs leads to synchronous inhibition of knee extensor and hip extensor motoneurons. Thus, knee extension occurs during hip extension in pocket scratching. Analogously, each ER and each IR is broadly tuned to a region of the rostral scratch receptive field and projects to both knee extensor and hip flexor motoneurons. Thus, knee extension occurs during hip flexion in rostral scratching. Because these propriospinal neurons are only broadly tuned, knee extensor motoneurons receive temporally overlapping excitation and inhibition from populations of propriospinal neurons tuned to different regions of the body surface, integrating these inputs to achieve the appropriate timing of knee extension within the hip activity cycle. Thus, the appropriate knee-hip synergy is not established prior to activation of motoneurons; integration in the motoneurons themselves contributes to forming the motor pattern. Recent experiments in electric fish have shown that signals from two separate populations of neurons responsible for increasing and decreasing the frequency of electric organ discharge are integrated only in last-order interneurons (Metzner, 1993); however, the motor pattern is apparently established at this point, prior to the activation of motoneurons.

The above analysis suggests that spinal circuitry involving activation of two sets of motoneurons by each propriospinal neuron could account for generation of the appropriate motor synergies underlying rostral scratching and pocket scratching without the need for knee control-related propriospinal neurons. Whether single turtle propriospinal neurons actually project to two sets of motoneurons is a question for future investigation. However, intracellular recordings from FT-KE (knee extensor), VP-HP (hip flexor), and HR-KF (hip extensor) motoneurons during fictive scratching have already provided supportive ev- 
idence for this hypothesis (Robertson and Stein, 1988). The membrane voltage trajectory of FT-KE motoneurons was similar to the voltage trajectory of VP-HP motoneurons during fictive rostral scratching, and was similar to the voltage trajectory of HR-KF motoneurons during fictive pocket scratching. This demonstrates that knee extensor and hip flexor motoneurons receive similar inputs during fictive rostral scratching and that knee extensor and hip extensor motoneurons receive similar inputs during fictive pocket scratching, as suggested by the model in Figure $9 B$. In addition, in just those fictive rostral scratch cycles in which the HR-KF burst was missing (termed HR-KF deletions), a portion of the hyperpolarizing wave of the FT-KE voltage trajectory was also missing (Robertson and Stein, 1988, their Fig. 6A). These results suggested to the authors that knee and hip motoneurons may receive rhythmic inputs from the same set of interneurons.

The model shown in Figure $9 B$ also predicts that turtle knee extensor motoneurons integrate excitatory and inhibitory synaptic inputs that overlap temporally. Intracellular recordings from turtle hindlimb motoneurons have shown that FT-KE motoneurons, in particular, do receive temporally overlapping synaptic excitation and inhibition, at least during fictive rostral scratching (Robertson and Stein, 1988). The model in Figure $9 B$ is qualitatively consistent with the available evidence. A quantitative and detailed comparison of the model to this and other experimental evidence would be facilitated by computer simulations of the model's operation. Such simulations could also lead to additional predictions for the turtle spinal circuitry underlying selection and generation of different forms of scratching.

The finding that many descending propriospinal axons in the turtle hindlimb enlargement were rhythmically activated during fictive scratching agrees well with previous findings that most ventral spinocerebellar tract (VSCT) neurons (Arshavsky et al., 1978), most lumbar Ia inhibitory interneurons (Deliagina and Orlovsky, 1980), most unidentified lumbar neurons (Berkinblit et al., 1978a; Baev et al., 1981), and some descending propriospinal neurons with cervical or thoracic cell bodies (Berkinblit et al., 1977) in the cat were rhythmically activated during fictive scratching. Most VSCT neurons, Ia interneurons, and unidentified lumbar neurons generated bursts of action potentials separated by silent periods. The VSCT neurons (Arshavsky et al., 1978) and the unidentified lumbar neurons (Berkinblit et al., 1978a) were each divided into three functional groups, based on the phases of fictive scratching in which the neuron's bursts began and ended. In contrast, in the study of a small number of cat descending propriospinal neurons with cervical or thoracic cell bodies, most were not rhythmically modulated during fictive scratching, and those that were rhythmically modulated were only weakly so (Berkinblit et al., 1977). In the present study, descending propriospinal neurons in the turtle showed a wide range of strengths of rhythmic modulation.

\section{Phases of unit activity in ipsilateral and contralateral fictive scratching}

Many descending propriospinal neurons recorded were rhythmically activated during both ipsilateral and contralateral fictive scratching. This finding is somewhat surprising, because studies of scratching have generally focused on ipsilatcral neural circuitry. On the other hand, there are many propriospinal neurons with descending crossed axons in turtles (Kusuma and ten Donkelaar, 1980; Berkowitz and Stein, 1994a), as well as in lampreys
(Buchanan, 1982; Ohta et al., 1991), embryonic tadpoles (see Roberts, 1989), embryonic newts (Harper and Roberts, 1993), goldfish (Fetcho, 1991), lizards (ten Donkelaar and de Boer van Huizen, 1978; Kusuma and ten Donkelaar, 1980), chicks (Oppenheim et al., 1988), and mammals (Burton and Loewy, 1976; Molenaar, 1978; Molenaar and Kuypers, 1978; Matsushita et al., 1979; Menetrey et al., 1985; Hongo et al., 1989; Cassidy and Cabana, 1993). In addition, during turtle fictive scratching evoked by unilateral tactile stimulation, some hindlimb muscle nerves on the opposite side of the body are often activated with a clear rhythm (Fig. 6; see also Currie and Stein, 1989, their Fig. 5C,D; Berkowitz and Stein, 1994b). The contralateral VPHP bursts are typically weak; they usually alternate with the strong ipsilateral VP-HP bursts.

Several other lines of evidence demonstrate that contralateral motoneurons and muscles are active during scratching by the ipsilateral hindlimb. Sherrington (1910) observed contractions of contralateral hindlimb muscles during cat scratching; his impression was that this activity was "steady and maintained." O'Donovan et al. (1982) demonstrated rhythmic activity in rccordings from contralateral hindlimb muscles during cat scratching. Deliagina et al. (1981) demonstrated that some contralateral hindlimb motoneurons were rhythmically active during fictive cat scratching. In addition, Deliagina (1977) suggested that crossed descending propriospinal pathways in the cervical spinal cord are important for the initiation of cat scratching (evoked by tactile stimulation of the ear), but that lumbar descending propriospinal pathways involved in scratching are entirely ipsilateral. Berkinblit et al. (1978a) destroyed part of the cat lumbar (L3-L5) spinal gray matter unilaterally and noted that fictive scratching could still be evoked on the opposite side. Berkinblit et al. (1977) found that no descending propriospinal neurons with cervical or thoracic cell bodies were excited during contralateral tactile stimulation of the cat's ear or during contralateral fictive scratching, although thoracic cells could be inhibited; this study, however, involved only a small numbcr of propriospinal neurons. Thus, the present study is the first demonstration that some propriospinal circuitry is rhythmically activated during scratch motor patterns evoked by stimulation of either side of the body. It is possible that the spinal circuitry underlying scratching is substantially different in the turtle and the cat; however, further examination of the propriospinal circuitry involved in cat scratching may be useful.

Contralateral hindlimb movement during scratching might contribute a useful element to the behavior. For example, it may provide a counterbalance when the ipsilateral hindlimb moves. One of the postures that intact cats assume during scratching is a tripod posture in which the contralateral hindlimb contributes to supporting the animal (Kuhta and Smith, 1990). The contralateral neuronal activity also may be a reflection of general spinal motor control circuitry that has evolved to produce out of phase excitation and inhibition of homonymous muscles on the two sides during other behaviors. In any case, many descending propriospinal neurons may contribute to generation of the bilateral components of fictive scratching. For many such neurons, the unit's phase in the right hip flexor activity cycle during stimulation of the left side was similar to the unit's phase in the right hip flexor activity cycle during stimulation of the right side. For other neurons, the unit's phase in the right hip flexor activity cycle during left side stimulation was opposite its phase during right side stimulation. Fither or both groups of neurons might be involved in creating left-right alternation of 
homonymous muscle activity, depending on which motor pools they project to and the presence or absence of an interposed inhibitory interneuron. Alternatively, one group may contribute to left-right alternation of hindlimb movements, as occurs during forward swimming and forward walking, and the other group may contribute to left-right synchrony of hindlimb movements, as occurs during backward escape swimming and during simultaneous withdrawal of all four limbs and the head.

\section{Strengths of rhythmic modulation of unit activity}

Most descending propriospinal neurons tested generated spikes at a higher rate when they were active with weaker rhythmic modulation (Fig. 8). This finding seems counterintuitive. However, it may shed light on the mechanisms used in motor pattern generation in the turtle spinal cord. One possible explanation is that, for the higher single-unit firing rates observed, these propriospinal neurons (or neurons that synaptically activated them) had approached their peak firing rates. Thus, if these neurons were in fact saturated, additional rhythmic depolarization would not be reflected in the neuron's firing rate. If this were the case, it would suggest either that these neurons did not contribute to generating the very strongly rhythmic activity observed in motoneurons or that these neurons are normally active at lower rates. However, since this study used tactile stimulation of the body surface, rather than electrical stimulation within the nervous system, it is unlikely that the firing rates observed in these neurons were higher than they would be in the intact, behaving animal.

An altcrnate explanation is that rhythmic inhibition is more important than rhythmic excitation in turtle spinal cord pattern generation. In this scenario, pattern-generating neurons would receive excitatory inputs that were only weakly rhythmic in combination with inhibitory inputs that were more strongly rhythmic. If descending propriospinal neurons received different proportions of such excitatory and inhibitory signals during tactile stimulation of different sites, it could account for the observed relationship between firing rate and strength of rhythmic modulation: whenever a propriospinal neuron received a greater proportion of inhibition, it fired at a lower rate, but with stronger rhythmic modulation. This explanation receives support from the demonstrated importance of glycinergic inhibition in generation of rhythmic motor patterns in lampreys (Grillner and Wallen, 1980) and embryonic tadpoles (Roberts et al., 1985). These two explanations could be evaluated by intracellular recording from descending propriospinal neurons.

\section{References}

Arshavsky YI, Berkinblit MB, Fukson OI, Gelfand IM, Orlovsky GN (1972) Origin of modulation in neurones of the ventral spinocerebellar tract during locomotion. Brain Res 43:276-279.

Arshavsky YI, Gelfand IM, Orlovsky GN, Pavlova GA (1978) Messages conveyed by spinocerebellar pathways during scratching in the cat. II. Activity of neurons of the ventral spinocerebellar tract. Brain Res 151:493-506.

Baev KV, Degtyarenko AM, Zavadskaya TV, Kostyuk PG (1981) Activity of lumbosacral interneurons during fictitious scratching. Neurophysiology (Kiev) 13:45-52.

Batschelet E (1981) Circular statistics in biology. London: Academic.

Berkinblit MB, Deliagina TG, Orlovsky GN, Feldman AG (1977) Activity of propriospinal neurons during the scratch reflex in cats. Neurophysiology (Kiev) 9:381-387.

Berkinblit MB, Deliagina TG, Feldman AG, Gelfand IM, Orlovsky GN (1978a) Generation of scratching. 1. Activity of spinal interneurons during scratching. J Neurophysiol 41:1040-1057.
Berkinblit MB, Deliagina TG, Feldman AG, Gelfand IM, Orlovsky GN (1978b) Generation of scratching. II. Nonregular regimes of generation. J Neurophysiol 41:1058-1069.

Berkowitz A (1993) Descending propriospinal neurons in the turtle: cell body locations, funicular courses, and single-unit activity during two forms of fictive scratching. PhD thesis, Washington University, St. Louis.

Berkowitz A, Stein PSG (1990) Activity of spinal neurons with descending axons during fictive scratch in spinal turtles. Soc Neurosci Abstr 16:1091.

Berkowitz A, Stein PSG (1991) Bilateral activation of interneurons during fictive scratching in spinal turtles. Soc Neurosci Abstr 17:123.

Berkowitz A, Stein PSG (1992) Activity of descending propriospinal neurons is linked to the activity cycle of hip motor neurons during both rostral and pocket fictive scratching in turtles. Proceedings of the Third International Congress of Neuroethology, Abstr 309.

Berkowitz A, Stein PSG (1994a) Descending propriospinal axons in the hindlimb enlargement of the red-eared turtle: cells of origin and funicular courses. J Comp Neurol, in press.

Berkowitz A, Stein PSG (1994b) Activity of descending propriospinal axons in the turtle hindlimb enlargement during two forms of fictive scratching: broad tuning to regions of the body surface. $J$ Neurosci 14:5089-5104.

Buchanan JT (1982) Identification of interneurons with contralateral, caudal axons in the lamprey spinal cord: synaptic interactions and morphology. J Neurophysiol 47:961-975.

Burns MD, Usherwood PNR (1979) The control of walking in $\mathrm{Or}$ thoptera. II. Motor neurone activity in normal free-walking animals. J Exp Biol 79:69-98.

Burton H, Loewy AD (1976) Descending projections from the marginal cell layer and other regions of the monkey spinal cord. Brain Res 116:485-491.

Cassidy G, Cabana T (1993) The development of the long descending propriospinal projections in the opossum, Monodelphis domestica. Dev Brain Res 72:291-299.

Currie SN, Stein PSG (1989) Interruptions of fictive scratch motor rhythms by activation of cutaneous flexion reflex afferents in the turtle. J Neurosci 9:488-496.

Deliagina TG (1977) Central pathway of the scratch reflex in cats. Neurophysiology (Kiev) 9:470-471.

Deliagina TG, Feldman AG (1981) Activity of Renshaw cells during fictive scratch reflex in cat. Exp Brain Res 42:108-115.

Deliagina TG, Orlovsky GN (1980) Activity of Ia inhibitory interneurons during fictitious scratch reflex in the cat. Brain Res 193:439447.

Deliagina TG, Orlovsky GN, Perret C (1981) Efferent activity during fictitious scratch reflex in the cat. J Neurophysiol 45:595-604.

Dicaprio RA (1990) An interneurone mediating motor programme switching in the ventilatory system of the crab. J Exp Biol 154:517535 .

Dickinson PS, Moulins M (1992) Interactions and combinations between different networks in the stomatogastric nervous system. In: Dynamic biological networks: the stomatogastric nervous system (Harris-Warrick RM, Marder E, Selverston Al, Moulins M, eds), pp 140-160. Cambridge, MA: MIT Press.

Feldman AG, Orlovsky GN (1975) Activity of interneurons mediating reciprocal la inhibition during locomotion. Brain Res 84:181-194.

Fetcho JR (1991) Spinal network of the Mauthner cell. Brain Behav Evol 37:298-316.

Getting PA, Dekin MS (1985) Tritonia swimming. A model system for integration within rhythmic motor systems. In: Model neural networks and behavior (Selverston AI, ed), pp 3-20. New York: Plenum.

Graham D (1977) The effect of amputation and leg restraint on the free walking coordination of the stick insect Carausius morosus. J Comp Physiol 116:91-116.

Grelot L, Milano S, Portillo F, Miller AD (1993) Respiratory interneurons of the lower cervical (C4-C5) cord: membrane potential changes during fictive coughing, vomiting, and swallowing in the decerebrate cat. Pfluegers Arch 425:313-320.

Grillner S (1975) Locomotion in vertebrates: central mechanisms and reflex interaction. Physiol Rev 55:247-304.

Grillner S (1981) Control of locomotion in bipeds, tetrapods, and fish. In: Handbook of physiology, Sect 1, The nervous system, Vol 2, Motor control (Brooks V, ed), pp 1179-1236. Bethesda, MD: American Physiological Society. 
Grillner S, Wallen P (1980) Does the central pattern generation for locomotion in lamprey depend on glycine inhibition? Acta Physiol Scand 110:103-105.

Harper CE, Roberts A (1993) Spinal cord neuron classes in embryos of the smooth newt Triturus vulgaris: a horseradish peroxidase and immunocytochemical study. Philos Trans R Soc Lond [Biol] 340: 141-160.

Heinzel HG, Weimann JM, Marder E (1993) The behavioral repertoire of the gastric mill in the crab, Cancer pagurus: an in situ endoscopic and electrophysiological examination. J Neurosci 13:17931803.

Heitler WJ (1985) Motor programme switching in the crayfish swimmeret system. J Exp Biol 1 14:521-549.

Hennig RM (1992) Mechanisms of motor pattern switching in crickets: stridulation and flight. In: Neurobiology of motor programme selection (Kien J, McCrohan CR, Winlow W, eds), pp 105-122. Oxford: Pergamon.

Hongo T, Kitazawa S, Ohki Y, Sasaki M, Xi M (1989) A physiological and morphological study of premotor interneurones in the cutaneous reflex pathways in cats. Brain Res 505:163-166.

Kristan WB, Lockery SR, Wittenberg G, Brody D (1992) Making behavioural choices with interneurones in a distributed system. In: Neurobiology of motor programme selection (Kien J, McCrohan CR, Winlow W, eds), pp 170-200. Oxford: Pergamon.

Kuhta PC, Smith JL (1990) Scratch responses in normal cats: hindlimb kinematics and muscle synergies. J Neurophysiol 64:1653-1667.

Kusuma A, ten Donkelaar HJ (1980) Propriospinal fibers interconnecting the spinal enlargements in some quadrupedal reptiles. J Comp Neurol 193:871-891.

Marder E, Weimann JM (1992) Modulatory control of multiple task processing in the stomatogastric nervous system. In: Neurobiology of motor programme selection (Kien J, McCrohan CR, Winlow W, eds), pp 3-19. Oxford: Pergamon.

Mardia KV (1972) Statistics of directional data. London: Academic.

Matsushita M, Ikeda M, Hosoya Y (1979) The location of spinal neurons with long descending axons (long descending propriospinal tract neurons) in the cat: a study with the horseradish peroxidase technique. J Comp Neurol 184:63-79.

Menetrey D, de Pommery J, Roudier F (1985) Propriospinal fibers reaching the lumbar enlargement in the rat. Neurosci Lett 58:257261.

Metzer W (1993) The jamming avoidance response in Eigenmannia is controlled by two separate motor pathways. J Neurosci 13:18621878 .

Molenaar I (1978) The distribution of propriospinal neurons projecting to different motoneuronal cell groups in the cat's brachial cord. Brain Res 158:203-206.

Molenaar I, Kuypers HGJM (1978) Cells of origin of propriospinal fibers and of fibers ascending to supraspinal levels. An HRP study in cat and rhesus monkey. Brain Res 152:429-450.

Mortin LI, Stein PSG (1989) Spinal cord segments containing key elements of the central pattern generators for three forms of scratch reflex in the turtle. J Neurosci 9:2285-2296.

Mortin LI, Stein PSG (1990) Cutaneous dermatomes for the initiation of three forms of the scratch reflex in the spinal turtle. J Comp Neurol 295:515-529.

Mortin LI, Keifer J, Stein PSG (1985) Three forms of the scratch reflex in the spinal turtle: movement analyses. J Neurophysiol 53:150!1516.

Nonaka S, Miller AD (1991) Behavior of upper cervical inspiratory propriospinal neurons during fictive vomiting. J Neurophysiol 65 : $1492-1500$.

O'Donovan MJ, Pinter MJ, Dum RP, Burke RE (1982) Actions of FDL and FHL muscles in intact cats: functional dissociation between anatomical synergists. J Neurophysiol 47:1126-1143.

Ohta Y, Dubuc R, Grillner S (1991) A ncw population of neurons with crossed axons in the lamprey spinal cord. Brain Res 564:143148.

Oppenheim RW, Shneiderman A, Shimizu I, Yaginuma H (1988) Onset and development of intersegmental projections in the chick embryo spinal cord. J Comp Neurol 275:159-180.

Orlovsky GN (1972) Activity of vestibulospinal neurons during locomotion. Brain Res 46:85-98.

Pearson KG (1993) Common principles of motor control in vertebrates and invertebrates. Annu Rev Neurosci 16:265-297.

Pratt CA, Jordan LM (1987) Ia inhibitory interneurons and Renshaw cells as contributors to the spinal mechanisms of fictive locomotion. J Neurophysiol 57:56-71.

Ramirez JM, Pearson KG (1988) Generation of motor patterns for walking and flight in motoneurons supplying bifunctional muscles in the locust. J Neurobiol 19:257-282.

Roberts A (1989) The neurons that control axial movements in a frog embryo. Am Zool 29:53-63.

Roberts A, Dale N, Evoy WH, Soffe SR (1985) Synaptic potentials in motoneurons during fictive swimming in spinal Xenopus embryos. $\mathrm{J}$ Neurophysiol 54:1-10.

Robertson GA, Stein PSG (1988) Synaptic control of hindlimb motoneurones during three forms of the fictive scratch reflex in the turtle. J Physiol (Lond) 404:101-128.

Robertson GA, Mortin LI, Keifer J, Stein PSG (1985) Three forms of the scratch reflex in the spinal turtle: central generation of motor patterns. J Neurophysiol 53:1517-1534.

Sherrington CS (1910) Notes on the scratch-reflex of the cat. Q J Exp Physiol 3:213-220.

Soffe SR (1993) Two distinct rhythmic motor patterns are driven by common premotor and motor neurons in a simple vertebrate spinal cord. J Neurosci 13:4456-4469.

Soffe SR, Clarke JDW, Roberts A (1984) Activity of commissural interneurons in spinal cord of Xenopus embryos. J Neurophysiol 51: $1257-1267$.

Stein PSG (1989) Spinal cord circuits for motor pattern selection in the turtle. Ann NY Acad Sci 563:1-10.

Stein PSG, Grossman ML (1980) Central program for scratch reflex in turtle. J Comp Physiol 140:287-294.

ten Donkelaar HJ, de Boer-van Huizen R (1978) Cells of origin of propriospinal and ascending supraspinal fibers in a lizard (Lacerta galloti). Neurosci Lett 9:285-290. 